\title{
An Analysis of the Effects of Residential Photovoltaic Energy Systems on Home Sales Prices in California
}

Ben Hoen, Ryan Wiser, Peter Cappers and Mark Thayer

Environmental Energy

Technologies Division

\section{April 2011}

Download from http://eetd.lbl.gov/ea/emp/reports/lbnl-4476e.pdf

This work was supported by the Office of Energy Efficiency and Renewable Energy (Solar Energy Technologies Program) of the U.S. Department of Energy under Contract No. DE-AC02-05CH11231, by the National Renewable Energy Laboratory under Contract No. DEK-8883050, and by the Clean Energy States Alliance. 


\section{Disclaimer}

This document was prepared as an account of work sponsored by the United States Government. While this document is believed to contain correct information, neither the United States Government nor any agency thereof, nor The Regents of the University of California, nor any of their employees, makes any warranty, express or implied, or assumes any legal responsibility for the accuracy, completeness, or usefulness of any information, apparatus, product, or process disclosed, or represents that its use would not infringe privately owned rights. Reference herein to any specific commercial product, process, or service by its trade name, trademark, manufacturer, or otherwise, does not necessarily constitute or imply its endorsement, recommendation, or favoring by the United States Government or any agency thereof, or The Regents of the University of California. The views and opinions of authors expressed herein do not necessarily state or reflect those of the United States Government or any agency thereof, or The Regents of the University of California.

Ernest Orlando Lawrence Berkeley National Laboratory is an equal opportunity employer. 


\title{
An Analysis of the Effects of Residential Photovoltaic Energy Systems on Home Sales Prices in California
}

\author{
Prepared for the \\ Office of Energy Efficiency and Renewable Energy \\ Solar Energy Technologies Program \\ U.S. Department of Energy \\ and the \\ National Renewable Energy Laboratory \\ and the \\ Clean Energy States Alliance \\ Principal Authors: \\ Ben Hoen, Ryan Wiser and Peter Cappers \\ Ernest Orlando Lawrence Berkeley National Laboratory \\ 1 Cyclotron Road, MS 90R4000 \\ Berkeley, CA 94720-8136 \\ Mark Thayer \\ San Diego State University \\ 5500 Campanile Dr. \\ San Diego, CA 92182-4485
}

April 2011

This work was supported by the Office of Energy Efficiency and Renewable Energy (Solar Energy Technologies Program) of the U.S. Department of Energy under Contract No. DE-AC0205CH11231, by the National Renewable Energy Laboratory under Contract No. DEK-8883050, and by the Clean Energy States Alliance. 


\section{Acknowledgements}

This work was supported by the Office of Energy Efficiency and Renewable Energy (Solar Energy Technologies Program) of the U.S. Department of Energy under Contract No. DE-AC0205CH11231, by the National Renewable Energy Laboratory under Contract No. DEK-8883050, and by the Clean Energy States Alliance. For funding and supporting this work, we especially thank Jennifer DeCesaro (U.S. DOE), Robert Margolis (NREL), and Mark Sinclair (Clean Energy States Alliance). For providing the data that were central to the analysis contained herein, we thank Cameron Rogers (Fiserv), Joshua Tretter (Core Logic Inc.), Bob Schweitzer (Sammish), Eric Kauffman (CERES), James Lee and Le-Quyen Nguyen (CEC), Steven Franz and Jim Barnett (SMUD), and Sachu Constantine (formerly with the CPUC), all of whom were highly supportive and extremely patient throughout the complicated data aquistion process. Finally, we would like to thank the many external reviewers for providing valuable comments on an earlier draft version of the report. Of course, any remaining errors or omissions are our own. 


\begin{abstract}
An increasing number of homes with existing photovoltaic (PV) energy systems have sold in the U.S., yet relatively little research exists that estimates the marginal impacts of those PV systems on home sales prices. A clearer understanding of these effects might influence the decisions of homeowners considering installing PV on their home or selling their home with PV already installed, of home buyers considering purchasing a home with PV already installed, and of new home builders considering installing PV on their production homes. This research analyzes a large dataset of California homes that sold from 2000 through mid-2009 with PV installed. Across a large number of hedonic and repeat sales model specifications and robustness tests, the analysis finds strong evidence that California homes with PV systems have sold for a premium over comparable homes without PV systems. The effects range, on average, from approximately \$3.9 to \$6.4 per installed watt (DC) of PV, with most coalescing near \$5.5/watt, which corresponds to a home sales price premium of approximately $\$ 17,000$ for a relatively new 3,100 watt PV system (the average size of PV systems in the study). These average sales price premiums appear to be comparable to the investment that homeowners have made to install PV systems in California, which from 2001 through 2009 averaged approximately \$5/watt (DC), and homeowners with PV also benefit from electricity cost savings after PV system installation and prior to home sale. When expressed as a ratio of the sales price premium to estimated annual electricity cost savings associated with PV, an average ratio of 14:1 to 22:1 can be calculated; these results are consistent with those of the more-extensive existing literature on the impact of energy efficiency (and energy cost savings more generally) on home sales prices. The analysis also finds - as expected - that sales price premiums decline as PV systems age. Additionally, when the data are split between new and existing homes, a large disparity in premiums is discovered: the research finds that new homes with PV in California have demonstrated average premiums of \$2.3-2.6/watt, while the average premium for existing homes with PV has been more than \$6/watt. One of several possible reasons for the lower premium for new homes is that new home builders may also gain value from PV as a market differentiator, and have therefore often tended to sell PV as a standard (as opposed to an optional) product on their homes and perhaps been willing to accept a lower premium in return for faster sales velocity. Further research is warranted in this area, as well as a number of other areas that are highlighted.
\end{abstract}




\section{Table of Contents}

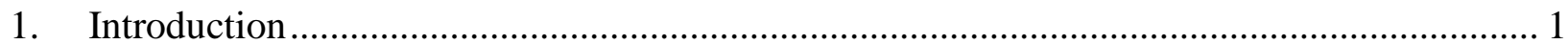

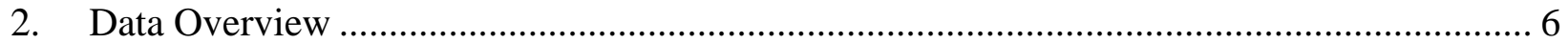

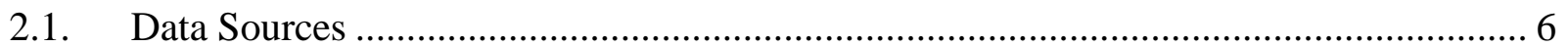

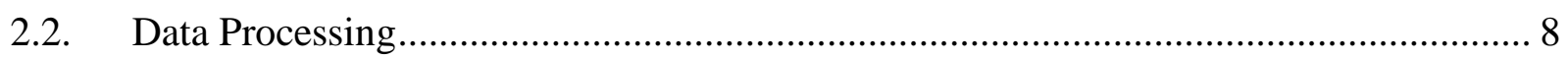

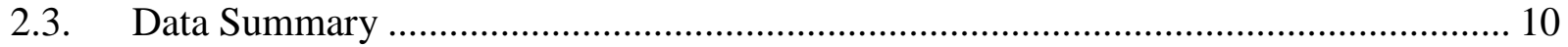

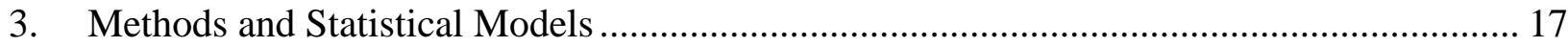

3.1. Methodological Overview ……………............................................................ 17

3.2. Variables Used in Models ...................................................................................... 18

3.3. Fixed and Continuous Effect Hedonic Models ............................................................ 20

3.4. New and Existing Home Models .............................................................................. 24

3.4.1. Difference-in-Difference Models........................................................................ 24

3.5. Age of the PV System for Existing Homes Hedonic Models ....................................... 27

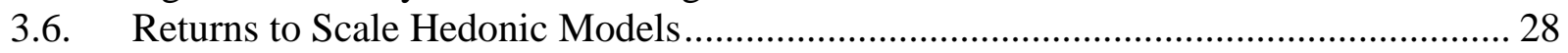

3.7. Model Summary.................................................................................................... 30

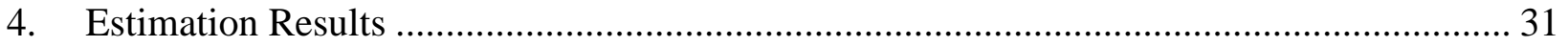

4.1. $\quad$ Fixed and Continuous Effect Hedonic Model Results.................................................. 32

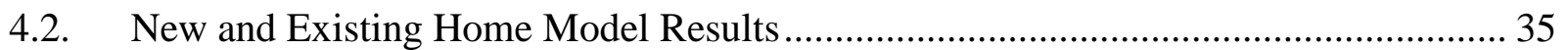

4.2.1. Difference-in-Difference Model Results ........................................................... 39

4.3. Age of PV System for Existing Home Hedonic Model Results .................................... 41

4.4. Returns to Scale Hedonic Model Results................................................................... 42

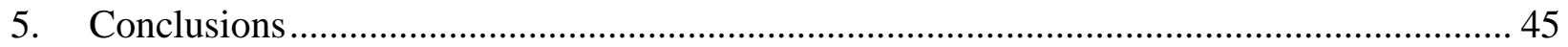

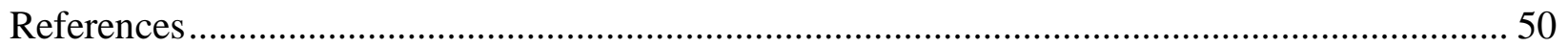




\section{List of Tables}

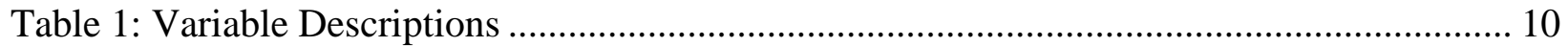

Table 2: Summary Statistics of Full Dataset.......................................................................... 12

Table 3: Summary Statistics of Repeat Sale Dataset ............................................................ 13

Table 4: Frequency Summary by California County …........................................................ 14

Table 5: Frequency Summary by Home Type, Utility and Sale Year ...................................... 16

Table 6: Difference-in-Difference Description.................................................................... 25

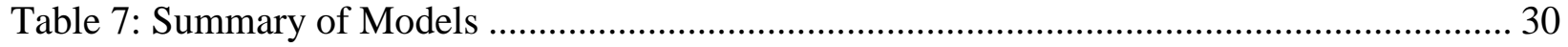

Table 8: Fixed and Continuous Base Hedonic Model Results with Robustness Tests................ 35

Table 9: New and Existing Home Base Hedonic Model Results with Robustness Tests............. 38

Table 10: Difference-in-Difference Model Results .............................................................. 41

Table 11: Age of PV System and Return to Scale Hedonic Model Results .............................. 44

\section{List of Figures}

Figure 1: Map of Frequencies of PV Homes by California County .......................................... 15

Figure 2: Fixed and Continuous Effect Base Model Results with Robustness Tests .................. 33

Figure 3: New and Existing Home Base Model Results with Robustness Tests ........................ 36

Figure 4: Existing Home Hedonic and Difference-in-Difference Model Results with Robustness

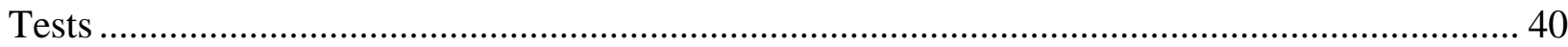

Figure 5: Estimated Ratios of Sale Price Premium to Annual Energy Cost Savings .................. 48 


\section{Introduction}

In calendar year 2010, approximately 880 megawatts (MW) ${ }^{1}$ of grid-connected solar photovoltaic (PV) energy systems were installed in the U.S. (of which approximately $30 \%$ were residential), up from 435 MW installed in 2009, yielding a cumulative total of 2,100 MW (SEIA \& GTM, 2011). California has been and continues to be the country's largest market for PV, with nearly 1000 MW of cumulative capacity. California is also approaching 100,000 individual PV systems installed, more than $90 \%$ of which are residential. An increasing number of these homes with PV have sold, yet to date, relatively little research has been conducted to estimate the existence and level of any premium to sales prices that the PV systems may have generated. One of the primary incentives for homeowners to install a PV system on their home, or for home buyers to purchase a home with a PV system already installed, is to reduce their electricity bills. However, homeowners cannot always predict if they will own their home for enough time to fully recoup their PV system investment through electricity bill savings. The decision to install a PV system or purchase a home with a PV system already installed may therefore be predicated, at least in part, on the assumption that a portion of any incremental investment in PV will be returned at the time of the home's subsequent sale through a higher sales price. Some in the solar industry have recognized this potential premium to home sales prices, and, in the absence of having solid research on PV premiums, have used related literature on the impact of energy efficiency investments and energy bill savings on home prices as a proxy for making the claim that residential PV systems can increase sales prices (e.g., Black, 2010).

The basis for making the claim that an installed PV system may produce higher residential selling prices is grounded in the theory that a reduction in the carrying cost of a home will translate, ceteris paribus, into the willingness of a buyer to pay more for that home. Underlying this notion is effectively a present value calculation of a stream of savings associated with the

\footnotetext{
${ }^{1}$ All references to the size of PV systems in this paper, unless otherwise noted, are reported in terms of direct current (DC) watts under standard test conditions (STC). This convention was used to conform to the most-common reporting conventions used outside of California. In California, PV systems sizes are often referred to using the California Energy Commission Alternating Current (CEC-AC) rating convention, which is approximately a multiple of 0.83 of the DC-STC convention, but depends on a variety of factors including inverter efficiency and realistic operating efficiencies for panels. A discussion of the differences between these two conventions and how conversions can be made between them is offered in Appendix A of Barbose et al., 2010.
} 
reduced electricity bills of PV homes, which can be capitalized into the value of the home. Along these lines, a number of studies have shown that residential selling prices are positively correlated with lower energy bills, most often attributed to energy related home improvements, such as energy efficiency investments (Johnson and Kaserman, 1983; Longstreth et al., 1984; Laquatra, 1986; Dinan and Miranowski, 1989; Horowitz and Haeri, 1990; Nevin and Watson, 1998; Nevin et al., 1999). The increased residential sales prices associated with lower energy bills and energy efficiency measures might be expected to apply to PV as well. Some homeowners have stated as much in surveys (e.g., CEC, 2002; McCabe and Merry, 2010), though the empirical evidence supporting such claims is limited in scope. Farhar et al. (2004a; 2008) tracked repeat sales of 15 "high performance” energy efficient homes with PV installed from one subdivision in San Diego and found evidence of higher appreciation rates, using simple averages, for these homes over comparable homes ( $n=12)$. More recently, Dastrop et al. (2010) used a hedonic analysis to investigate the selling prices of 279 homes with PV installed in the San Diego, California metropolitan area, finding clear evidence of PV premiums that averaged approximately $3 \%$ of the total sales price of non-PV homes, which translates into \$4.4 per installed PV watt (DC).

In addition to energy savings, higher selling prices might be correlated with a "cachet value" based on the "green” attributes that come bundled with energy-related improvements (e.g., helping combat global warming, impressing the neighbors, etc.). A number of recent papers have investigated this correlation. Eichholtz et al. (2009, 2011) analyzed commercial green properties in the U.S, and Brounen and Kok (2010) and Griffin et al. (2009) analyzed green labeled homes in the Netherlands and Portland, Oregon, respectively, each finding premiums, which, in some cases, exceeded the energy savings (Eichholtz et al., 2009, 2011; Brounen and Kok, 2010). Specifically related to PV, Dastrop et al. (2010) found higher premiums in communities with a greater share of Toyota Prius owners and college grads, indicating, potentially, the presence of a cachet value to the systems over and above energy savings. It is therefore reasonable to believe that buyers of PV homes might price both the energy savings and the green cachet into their purchase decisions. 
Of course there is both a buyer and a seller in any transaction, and the sellers of PV homes might be driven by different motivations than the buyers. Specifically, recouping the net installed cost of the PV system (i.e., the cost of PV installation after deducting any available state and federal incentives) might be one driver for sellers. In California, the average net installed cost of residential PV hovered near \$5/watt (DC) from 2001 through 2009 (Barbose et al., 2010). Adding slightly to the complexity, the average net installed cost of PV systems has varied to some degree by the type of home, with PV systems installed on new homes in California enjoying approximately a \$1/watt lower average installed cost than PV systems installed on existing homes in retrofit applications (Barbose et al., 2010). Further, sellers of new homes with PV (i.e., new home developers) might be reluctant to aggressively increase home sale prices for installed PV systems because of the burgeoning state of the market for PV homes and concern that more aggressive pricing might slow home sales, especially if PV is offered as a standard (not optional) product feature (Farhar and Coburn, 2006). At the same time, the possible positive impact of PV on product differentiation and sales velocity may make new home developers willing to sell PV at below the net installed cost of the system. After all, some studies that have investigated whether homes with PV (often coupled with energy efficient features) sell faster than comparable homes without PV have found evidence of increased velocity due to product differentiation (Dakin et al., 2008; SunPower, 2008). Finally, as PV systems age, and sellers (i.e., homeowners) recoup a portion of their initial investment in the form of energy bill savings (and, related, the PV system's lifespan decreases), the need (and ability) to recoup the full initial investment at the time of home sale might decrease. On net, it stands to reason that premiums for PV on new homes might be lower than those for existing homes, and that older PV systems might garner lower premiums than newer PV systems of the same size.

Though a link between selling prices and some combination of energy cost savings, green cachet, recouping the net installed cost of PV, seller attributes, and PV system age likely exists, the existing empirical literature in this area, as discussed earlier, has largely focused on either energy efficiency in residential and commercial settings, or PV in residential settings but in a limited geographic area (San Diego), with relatively small sample sizes. Therefore, to date, establishing a reliable estimate for the PV premiums that may exist across a wide market of homes has not 
been possible. Moreover, establishing premiums for new versus existing homes with PV has not yet been addressed.

Additionally, research has not investigated whether there are increasing or decreasing returns on larger PV systems, and/or larger homes with the same sized PV systems, nor has research been conducted that investigates whether older PV systems garner lower premiums. In the case of returns to scale on larger PV systems, it is not unreasonable to expect that any increase in value for PV homes may be non-linear as it relates to PV system size. For example, if larger PV systems push residents into lower electricity price tiers ${ }^{2}$, energy bill savings could be diminished on the margin as PV system size increases. This, in turn, might translate into smaller percentage increases in residential selling prices as PV systems increase in size, and therefore a decreasing return to scale. Larger PV systems might also enjoy some economies of scale in installation costs, which, in turn, might translate into lower marginal premiums at the time of home sale as systems increase in size - a decreasing return to scale. Additionally, "cachet value", to the degree that it exists, is likely to be somewhat insensitive to system size, and therefore might act as an additional driver to decreasing returns to scale. Somewhat analogously, PV premiums may be related to the number of square feet of living area in the home. Potentially, as homes increase in size, energy use can also be expected to increase, leading homeowners to be subjected to higher priced electricity rate tiers and therefore greater energy bill savings for similarly sized PV systems. Finally, as discussed previously, as PV systems age, and both a portion of the initial investment is recouped and the expected life and operating efficiency of the systems decrease, home sales price premiums might be expected to decline.

To explore these possible relationships, we investigate the residential selling prices across the state of California of approximately 2,000 homes with existing PV systems against a comparable set of approximately 70,000 non-PV homes. The sample is drawn from 31 California counties, with PV home sales transaction dates of 2000 through mid-2009. We apply a variety of hedonic pricing (and repeat sales) models and sample sets to test and bound the possible effects of PV on residential sales prices and to increase the confidence of the findings. Using these tools, we also

\footnotetext{
${ }^{2}$ Many California electric utilities provide service under tiered residential rates that charge progressively higher prices for energy as more of it is used.
} 
explore whether the effects of PV systems on home prices are impacted by whether the home is new or existing, by the size of either the PV system or the home itself, and finally by how old the PV system is when the home sells. ${ }^{3}$ It should be stated that this research is not intended to disentangle the specific effects of energy savings, green cachet, recovery of the cost of installation, or seller motivations, but rather to establish credible estimates of aggregate PV residential sales price effects.

The paper begins with a discussion of the data used for the analyses (Section 2). This is followed by a discussion of the empirical basis for the study (Section 3), where the variety of models and sample sets are detailed. The paper then turns to a discussion of the results and their potential implications (Section 4), and finally offers some concluding remarks with recommendations for future research (Section 5).

\footnotetext{
${ }^{3}$ Due to the limited sample of PV home sales in many individual years, the results presented in this report reflect average impacts over the entire 2000-09 period (after controlling for housing market fluctuations).
} 


\section{Data Overview}

To estimate the models described later, a dataset of California homes is used that joins the following five different sets of data: (1) PV home addresses and system information from three organizations that have offered financial incentives to PV system owners in the state; (2) real estate information that is matched to those addresses and that also includes the addresses of and information on non-PV homes nearby; (3) home price index data that allow inflation adjustments of sale prices to 2009 dollars; (4) locational data to map the homes with respect to nearby neighborhood/environmental influences; and (5) elevation data to be used as a proxy for "scenic vista." Each of these data sources is described below, as are the data processing steps employed, and the resulting sample dataset.

\subsection{Data Sources}

The California Energy Commission (CEC), the California Public Utilities Commission (CPUC), and the Sacramento Municipal Utility District (SMUD) each provide financial incentives under different programs to encourage the installation of PV systems in residential applications, and therefore have addresses for virtually all of those systems, as well as accompanying data on the PV systems. ${ }^{4}$ Through these programs, Berkeley Laboratory was provided information on approximately 42,000 homes where PV was installed, only a fraction of which (approximately 9\%) subsequently sold with the PV system in place. The data provided included: address (street, street number, city, state and zip); incentive application and PV system install and operational dates; PV system size; and delineations as to whether the home was new or existing at the time the PV system was installed (where available).

\footnotetext{
${ }^{4}$ The CEC and CPUC have both been collecting data on PV systems installed on homes in the utility service areas of investor owned utilities (e.g., PG\&E, SCE, SDG\&E) for which they have provided incentives, as have some of California's publicly owned utilities (e.g., SMUD) that offer similar incentives. The CEC began administering its incentive program in 1998, and provided rebates to systems of various sizes for both residential and commercial customers. The CPUC began its program in 2001, initially focusing on commercial systems over $30 \mathrm{~kW}$ in size. In January 2007, however, the CEC began concentrating its efforts on new residential construction through its New Solar Home Partnership program, and the CPUC took over the administration of residential retrofit systems through the California Solar Initiative program. Separately, SMUD has operated a long-standing residential solar rebate program, but of smaller size than the efforts of the CEC and CPUC.
} 
These addresses were then matched to addresses as maintained by Core Logic (CL) $)^{5}$, which they aggregate from both the California county assessment and deed recorder offices. Once matched, CL provided real estate information on each of the California PV homes, as well as similar information on approximately 150,000 non-PV homes that were located in the same (census) block group and/or subdivision as the matched PV homes. The data for both of these sets of homes included:

- $\quad$ address (e.g., street, street number, city, state and zip+4 code);

- most recent ("second") sale date and amount;

- previous ("first”) sale date and amount (if applicable);

- home characteristics (where available) (e.g., acres, square feet of living area, bathrooms, and year built);

- assessed value;

- parcel land use (e.g., commercial, residential);

- $\quad$ structure type (e.g., single family residence, condominium, duplex);

- housing subdivision name (if applicable) ${ }^{6}$; and

- census tract and census block group.

These data, along with the PV incentive provider data, allowed us to determine if a home sold after a PV system was installed ("second" sale). 3,657 such homes were identified in total, and these homes, therefore, represent the possible sample of homes on which our analysis focused. A subset of these data for which "first" sale information was available and for which a PV system had not yet been installed as of this "first" sale, were culled out. These "repeat sales" were also used in the analysis, as will be discussed in Section 3.

In addition to the PV and real estate data, Berkeley Laboratory obtained from Fiserv a zip-codelevel weighted repeat sales index of housing prices in California from 1970 through mid-2009, by quarter. These indices, where data were available, were differentiated between low, middle,

\footnotetext{
${ }^{5}$ More information about this product can be obtained from http://www.corelogic.com/. Note that Core Logic, Inc. was formerly known as First American Core Logic.

${ }^{6}$ In some cases the same subdivisions were referred to using slightly different names (e.g., "Maple Tree Estates" \& "Maple Trees Estates"). Therefore, an iterative process of matching based on the names, the zip code, and the census tract were used to create "common" subdivision names, which were then used in the models, as discussed later.
} 
and high home price tiers, to accommodate the different appreciation/depreciation rates of market segments. Using these indices, all sale prices were adjusted to Q1, 2009 prices. ${ }^{7}$

From Sammamish Data, Berkeley Laboratory purchased x/y coordinates for each zip +4 code, which allowed the mapping of addresses to street level accuracy. ${ }^{8}$ Additionally, Berkeley Laboratory obtained from the California Natural Resources Agency (via the California Environmental Resources Evaluation System, CERES) a 30 meter level Digital Elevation Map (DEM) for the state of California. ${ }^{9}$ Combining these latter two sets of data, a street level elevation could be obtained for each home in the dataset, which allowed the construction of a variable defined as the elevation of a home relative to its (census) block group. This relative elevation served as a proxy for "scenic vista", a variable used in the analysis.

\subsection{Data Processing}

Data cleaning and preparation for final analysis was a multifaceted process involving selecting transactions where all of the required data fields were fully populated, determining if sales of PV homes occurred after the PV system was installed, matching the homes to the appropriate index, ensuring the populated fields were appropriately coded, and finally, eliminating obviously suspicious observations (e.g., not arms length transactions, outliers, etc.). Initially provided were a total of 150,000 detached single family residential sale records without PV and a total of 3,657 with PV. These totals, however, were substantially reduced (by approximately 65,000 records, 1,400 of which were PV sales) because of missing/erroneous core characteristic data (e.g., sale date, sale price, year built, square feet). ${ }^{10}$ Additionally, the final dataset was reduced (by approximately 14,000 records, 300 of which were PV sales) because some sales occurred outside the range of the index that was provided (January 1970 to June 2009). Moreover, to focus our analysis on more-typical California homes and minimize the impact of outliers or potential data-

\footnotetext{
${ }^{7}$ The inflation adjustment instrument used for this analysis is the Fiserv Case-Shiller Index. This index is a weighted repeat sales index, accumulated quarterly at, optimally, the zip code level over three home price tiers (e.g., low, middle and high prices). More information can be found at: http://www.caseshiller.fiserv.com/indexes.aspx

${ }^{8}$ More information about this product can be obtained from http://www.sammdata.com/

${ }^{9}$ More information about this product can be obtained from http://www.ceres.ca.gov/

${ }^{10}$ Examples of "erroneous" data might include a year built or sale date that is in the future (e.g., "2109" or "Jan 1, 2015", respectively), or large groups of homes that were listed at the same price in the same year in the same block group that were thought to be "bulk" sales and therefore not valid for our purposes.
} 
entry errors on our results, observations not meeting the following criteria were screened out (see Table 1 for variable descriptions):

- the inflation adjusted most recent (second) sale price (asp2) is between $\$ 85,000$ and $\$ 2,500,000 ;^{11}$

- the number of square feet (sqft) is greater than 750;

- asp2 divided by sqft is between $\$ 40$ and $\$ 1,000$;

- the number of acres is less than 25 and greater than sqft divided by 43,560 (where one acre equals 43,560 sqft); ${ }^{12}$

- $\quad$ the year the home was built (yrbuilt) is greater than 1900;

- the age of the home (in years) at the time of the most recent sale (ages2) is greater than or equal to negative one;

- the number of bathrooms (baths) is greater than zero and less than ten;

- the size of the PV system (size) is greater than 0.5 and less than 10 kilowatts $(\mathrm{kW})$;

- each block group contains at least one PV home sale and one non-PV home sale; and

- the total assessed value (avtotal), as reported by the county via Core Logic, is less than or equal to the predicted assessed value $(p a v)$, where $p a v=s p 2^{*} 1.02^{\wedge}\left(2010\right.$-year of sale). ${ }^{13}$

In addition, the repeat sales used in the analysis had to meet the following criteria:

- the difference in sale dates (sddif) between the most recent (second) sale date (sd2) and the previous (first) sale date (sd1) is less than 20 years;

- $\quad \mathrm{PV}$ is not installed on the home as of $s d 1$; and

- the adjusted annual appreciation rate (adjaar) is between -0.14 and 0.3 (where adjaar = $\ln ($ asp2/asp1)/(sddif/365), which corresponds to the 5th and 95th percentile for the distribution of adjaar. ${ }^{14}$

\footnotetext{
${ }^{11}$ An alternative screen was tested that limited the data to homes under $\$ 1$ million (leaving $90 \%$ of the data) and $\$ 600,000$ (leaving $75 \%$ ), with no significant change to the results.

${ }^{12}$ An alternative screen that incorporated the number of stories for the home along with the number of square feet in calculating the "footprint", and therefore allowed smaller parcels to be used, was also explored, with no significant change in results.

${ }^{13}$ This screen was intended to help ensure that homes that had significant improvements since the most recent sale, which would be reflected in a higher assessed value than would otherwise be the maximum allowable under California property tax law, were removed from the dataset. The screen was not applied to homes that sold in 2009, however, because, in those cases, assessed values often had not been updated to reflect the most recent sale.

${ }^{14}$ This final screen was intended to remove homes that had unusually large appreciation or deprecations between sales, after adjusting for inflation, which could indicate that the underlying home characteristics between the two sales changed (e.g., an addition was added, the condition of the home dramatically worsened, etc.), or the data were erroneous.
} 
Table 1: Variable Descriptions

\begin{tabular}{|l|l|}
\hline Variable & Description \\
\hline acre & size of the parcel (in acres) \\
\hline acregt1 & number of acres more than one \\
\hline acrelt1 & number of acres less than one \\
\hline adjaar & adjusted annual appreciation rate \\
\hline ages2 & age of home as of sd2 \\
\hline ages2sqr & ages2 squared \\
\hline asp1 & inflation adjusted sp1 (in 2009 dollars) \\
\hline asp2 & inflation adjusted sp2 (in 2009 dollars) \\
\hline avtotal & total assessed value of the home \\
\hline bath & number of bathrooms \\
\hline bgre_100 & relative elevation to other homes in block group (in 100s of feet) \\
\hline elev & elevation of home (in feet) \\
\hline lasp1 & natural log of asp1 \\
\hline lasp2 & natural log of asp2 \\
\hline pav & predicted assessed value \\
\hline pvage & age of the PV system at the time of sale \\
\hline sd1 & first sale date \\
\hline sd2 & second sale date \\
\hline sddif & number of days separating sd1 and sd2 \\
\hline size & size (in STC DC kW) of the PV system \\
\hline sp1 & first sale price (not adjusted for inflation) \\
\hline sp2 & second sale price (not adjusted for inflation) \\
\hline sqft & size of living area \\
\hline sqft_1000 & size of living area (in 1000s of square feet) \\
\hline yrbuilt & year the home was built \\
\hline
\end{tabular}

\subsection{Data Summary}

The final full dataset includes a total of 72,319 recent sales, 1,894 of which are PV homes and 70,425 of which are non-PV (see Table 2). The homes with PV systems are distributed evenly between new (51\%) and existing (49\%) home types, while the non-PV homes are weighted toward existing homes (62\%) over new (38\%) (see Table 5). The final repeat sales dataset of homes selling twice total 28,313 homes, of which 394 are PV and 27,919 are non-PV (see Table 3).

As indicated in Table 2, the average non-PV home in the full sample (not the repeat sales sample) sold for $\$ 584,740$ (unadjusted) in late 2005 , which corresponds to $\$ 480,862$ (adjusted) 
in 2009 dollars. ${ }^{15}$ This "average” home is built in 1986, is 19 years old at the time of sale, has 2,200 square feet of living space, has 2.6 bathrooms, is situated on a parcel of 0.3 acres, and is located at the mean elevation of the other homes in the block group. On the other hand, the average PV home in the full sample sold for \$660,222 in early 2007, which corresponds to \$537,442 in 2009 dollars. Therefore, this “average” PV home, as compared to the "average” non-PV home, is higher in value. This difference might be explained, in part, by the fact that the average PV home is slightly younger at the time of sale (by two years), slightly bigger (by 200 square feet), has more bathrooms (by 0.3), is located on a parcel that is slightly larger (by 0.06 acres), and, of course, has a PV system (which is, on average, 3,100 watts and 1.5 years old). ${ }^{16}$

The repeat sale dataset, as summarized in Table 3, shows similar modest disparities between PV and non-PV homes, with the "average” PV homes selling for more (in 2009 \$) in both the first and second sales. Potentially more telling, though, non-PV homes show a slight depreciation (of -1.4\%) between sales after adjusting for inflation, while PV homes show a modest appreciation (of 3.2\%). Average PV homes in the sample are found to be slightly bigger (by 100 square feet), occupy a slightly larger parcel (by 0.2 acres), older (by 10 years), and, of course, have a PV system (which is, on average, 4,030 watts and 2.5 years old).

Focusing on the full dataset geographically (see Table 4 and Figure 1), we find that it spans 31 counties with the total numbers of PV and non-PV sales ranging from as few as nine (Humboldt) to as many as 11,991 (Placer). The dataset spans 835 separate (census) block groups (not shown in the table), though only 162 (18.7\%) of these block groups contain subdivisions with at least one PV sale. Within the block groups that contain subdivisions with PV sales there are 497 subdivision-specific delineations. As shown in Table 5, the data on home sales are fairly evenly split between new and existing home types, are located largely within four utility service areas,

\footnotetext{
${ }^{15}$ The adjusted values, which are based on a housing price index, demonstrate the large-scale price collapse in the California housing market post 2005; that is, there has been significant housing price depreciation.

${ }^{16}$ Age of PV system at the time of sale is determined by comparing the sale date and ideally an "installation date", which corresponds to the date the system was operational, but, in some cases, the only date obtained was the "incentive application date", which might precede the installation date by more than one year. For this reason the age of the system reported for this research is lower than the actual age.
} 
with the largest concentration in PG\&E's territory, and occurred over eleven years, with the largest concentration of PV sales occurring in 2007 and 2008.

In summary, the full dataset shows higher sales prices for the average PV home than the average non-PV home, while the repeat sales dataset shows positive appreciation between sales for PV homes, but not for non-PV homes. Though these observations seem to indicate that a PV sales price premium exists, these simple comparisons do not take into account the other underlying differences between PV and non-PV homes (e.g., square feet), their neighborhoods, and the market conditions surrounding the sales. The hedonic and difference-in-difference statistical models discussed in the following section are designed to do just that.

Table 2: Summary Statistics of Full Dataset

\begin{tabular}{|c|c|c|c|c|c|}
\hline \multirow[b]{2}{*}{ Variable } & \multicolumn{5}{|c|}{ Non-PV Homes } \\
\hline & $n$ & Mean & Std. Dev. & Min & Max \\
\hline acre & 70425 & 0.3 & 0.8 & 0.0 & 24.8 \\
\hline acregt1 & 70425 & 0.1 & 0.7 & 0.0 & 23.8 \\
\hline acrelt1 & 70425 & 0.2 & 0.2 & 0.0 & 1.0 \\
\hline ages 2 & 70425 & 19 & 23.3 & -1 & 108 \\
\hline ages2sqr & 70425 & 943 & 1681 & 0 & 11881 \\
\hline asp2 & 70425 & \begin{tabular}{ll|}
$\$ 480,862$ \\
\end{tabular} & \begin{tabular}{|l|l|}
$\$ 348,530$ \\
\end{tabular} & 85,007 & $\$ 2,498,106$ \\
\hline avtotal & 70425 & $\$ 497,513$ & $\$ \quad 359,567$ & 10,601 & $\$ 3,876,000$ \\
\hline bath & 70425 & $\begin{array}{r}2.6 \\
\end{array}$ & \begin{tabular}{|r|}
0.9 \\
\end{tabular} & 1 & 9 \\
\hline bgre_100 & 70425 & 0.0 & 1.2 & -18.0 & 19.0 \\
\hline elev & 70425 & 424 & 598 & 0 & 5961 \\
\hline lasp2 & 70425 & 12.9 & 0.6 & 11.4 & 14.7 \\
\hline pvage & 70425 & 0 & 0 & 0 & 0 \\
\hline sd2 & 70425 & 9/30/2005 & 793 days & $1 / 7 / 1999$ & $6 / 30 / 2009$ \\
\hline size & 70425 & 0 & 0 & 0 & 0 \\
\hline sp2 & 70425 & $\$ 584,740$ & $\$ 369,116$ & 69,000 & $\$ 4,600,000$ \\
\hline sqft_1000 & 70425 & 2.2 & 0.9 & 0.8 & 9.3 \\
\hline \multirow[t]{2}{*}{ yrbuilt } & 70425 & 1986 & 23 & 1901 & 2009 \\
\hline & \multicolumn{5}{|c|}{ PV Homes } \\
\hline Variable & $n$ & Mean & Std. Dev. & Min & Max \\
\hline acre & 1894 & 0.4 & 1.0 & 0.0 & 21.6 \\
\hline acregt1 & 1894 & 0.1 & 0.9 & 0.0 & 20.6 \\
\hline acrelt1 & 1894 & 0.2 & 0.2 & 0.0 & 1.0 \\
\hline ages 2 & 1894 & 17.3 & 24.5 & -1 & 104 \\
\hline ages 2sqr & 1894 & 937 & 1849 & 0 & 11025 \\
\hline asp2 & 1894 & $\$ \quad 537,442$ & $\$ 387,023$ & 85,973 & $\$ 2,419,214$ \\
\hline avtotal & 1894 & $\$ \quad 552,052$ & $\$ \quad 414,574$ & 23,460 & $\$ 3,433,320$ \\
\hline bath & 1894 & 2.9 & 1 & 1 & 7 \\
\hline bgre_100 & 1894 & 0.2 & 1.3 & -10.0 & 17.9 \\
\hline elev & 1894 & 414 & 584 & 0 & 5183 \\
\hline lasp2 & 1894 & 13.0 & 0.6 & 11.4 & 14.7 \\
\hline pvage & 1894 & 1.5 & \begin{tabular}{r|}
2.0 \\
\end{tabular} & -1.0 & 9.0 \\
\hline sd2 & 1894 & $3 / 28 / 2007$ & 622 days & $8 / 1 / 2000$ & $6 / 29 / 2009$ \\
\hline size & 1894 & 3.1 & 1.6 & 0.6 & 10.0 \\
\hline sp2 & 1894 & $\$ \quad 660,222$ & $\begin{array}{|ll|} & 435,217 \\
\end{array}$ & 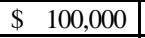 & $\$ 3,300,000$ \\
\hline sqft_1000 & 1894 & $\begin{array}{r}2.4 \\
\end{array}$ & \begin{tabular}{r|}
0.9 \\
\end{tabular} & \begin{tabular}{|r|}
0.8 \\
\end{tabular} & 11.0 \\
\hline yrbuilt & 1894 & 1989 & 25 & 1904 & 2009 \\
\hline
\end{tabular}


Table 3: Summary Statistics of Repeat Sale Dataset

\begin{tabular}{|c|c|c|c|c|c|}
\hline & \multicolumn{5}{|c|}{ Non-PV Homes } \\
\hline Variable & $n$ & Mean & Std. Dev. & Min & Max \\
\hline acre & 27919 & 0.3 & 0.7 & 0.0 & 23.2 \\
\hline acregt1 & 27919 & 0.1 & 0.6 & 0.0 & 22.2 \\
\hline acrelt1 & 27919 & 0.2 & 0.2 & 0.0 & 1.0 \\
\hline ages 2 & 27919 & 23.6 & 22.7 & 0 & 108 \\
\hline ages2sqr & 27919 & 1122.0 & 1775.0 & 1.0 & 11881.0 \\
\hline asp1 & 27919 & $\$ 488,127$ & $\$ 355,212$ & 85,398 & $\$ 2,495,044$ \\
\hline asp2 & 27919 & $\$ 481,183$ & $\$ 347,762$ & 85,007 & $\$ 2,472,668$ \\
\hline avtotal & 27919 & $\$ \quad 498,978$ & $\$ 360,673$ & 35,804 & $\$ 3,788,511$ \\
\hline bath & 27919 & 2.5 & 0.8 & 1 & 9 \\
\hline bgre_100 & 27919 & 0.0 & 1.3 & -17.7 & 19.0 \\
\hline elev & 27919 & 426 & 588 & 0 & 5961 \\
\hline lasp1 & 27919 & 12.9 & 0.6 & 11.4 & 14.7 \\
\hline lasp2 & 27919 & 12.9 & 0.6 & 11.4 & 14.7 \\
\hline pvage & 27919 & 0 & 0 & 0 & 0 \\
\hline sd1 & 27919 & $5 / 5 / 2001$ & 1780 days & $11 / 1 / 1984$ & $12 / 11 / 2008$ \\
\hline sd2 & 27919 & $5 / 14 / 2006$ & 786 days & 3/11/1999 & $6 / 30 / 2009$ \\
\hline sddif & 27919 & 1835 & 1509 & 181 & 7288 \\
\hline size & 27919 & 0 & 0 & 0 & 0 \\
\hline sp1 & 27919 & $\$ \quad 444,431$ & $\$ \quad 287,901$ & 26,500 & $\$ 2,649,000$ \\
\hline sp2 & 27919 & $\$ 577,843$ & $\$ 371,157$ & 69,000 & $\$ 3,500,000$ \\
\hline sqft_1000 & 27919 & 2.1 & 0.8 & 0.8 & 7.7 \\
\hline yrbuilt & 27919 & 1982 & 23 & 1901 & 2008 \\
\hline
\end{tabular}

\begin{tabular}{|c|c|c|c|c|c|}
\hline \multirow[b]{2}{*}{ Variable } & \multicolumn{5}{|c|}{ PV Homes } \\
\hline & $n$ & Mean & Std. Dev. & Min & Max \\
\hline acre & 394 & 0.5 & 1.4 & 0.0 & 21.6 \\
\hline acregt1 & 394 & 0.2 & 1.3 & 0.0 & 20.6 \\
\hline acrelt1 & 394 & 0.2 & 0.2 & 0.0 & 1.0 \\
\hline ages 2 & 394 & 34.6 & 25.6 & 1 & 104 \\
\hline ages2sqr & 394 & 1918.0 & 2336.0 & 4.0 & 11025.0 \\
\hline asp1 & 394 & $\$ 645,873$ & $\$ 417,639$ & $\$ 110,106$ & $\$ 2,339,804$ \\
\hline asp2 & 394 & $\$ \quad 666,416$ & $\$ 438,544$ & $\$ \quad 91,446$ & $\$ 2,416,498$ \\
\hline avtotal & 394 & $\$ \quad 682,459$ & $\$ 478,768$ & 51,737 & $\$ 3,433,320$ \\
\hline bath & 394 & 2.6 & 0.9 & 1 & 7 \\
\hline bgre_100 & 394 & 0.1 & 1.6 & -5.5 & 17.9 \\
\hline elev & 394 & 479 & 581 & 3 & 3687 \\
\hline lasp1 & 394 & 13.2 & 0.6 & 11.6 & 14.7 \\
\hline lasp2 & 394 & 13.2 & 0.6 & 11.4 & 14.7 \\
\hline pvage & 394 & 2.5 & 1.6 & -1.0 & 9.0 \\
\hline sd1 & 394 & 11/22/1999 & 1792 days & 11/30/1984 & $1 / 7 / 2008$ \\
\hline sd2 & 394 & $1 / 9 / 2007$ & 672 days & $8 / 1 / 2000$ & $6 / 29 / 2009$ \\
\hline sddif & 394 & 2605 & 1686 & 387 & 7280 \\
\hline size & 394 & 4.03 & 1.94 & 0.89 & 10 \\
\hline sp1 & 394 & $\$ 492,368$ & $\$ 351,817$ & \begin{tabular}{ll|}
$\$$ & 81,500 \\
\end{tabular} & $\$ 2,500,000$ \\
\hline sp2 & 394 & $\$ 800,359$ & $\$ 489,032$ & $\$ 121,000$ & $\$ 3,300,000$ \\
\hline sqft_1000 & 394 & 2.2 & 0.8 & 0.8 & 5.3 \\
\hline yrbuilt & 394 & 1972 & 26 & 1904 & 2008 \\
\hline
\end{tabular}


Table 4: Frequency Summary by California County

\begin{tabular}{|l|r|r|r|}
\hline CA County & Non-PV & PV & Total \\
\hline Alameda & 4,826 & 153 & $\mathbf{4 , 9 7 9}$ \\
\hline Butte & 457 & 12 & $\mathbf{4 6 9}$ \\
\hline Contra Costa & 5,882 & 138 & $\mathbf{6 , 0 2 0}$ \\
\hline El Dorado & 938 & 85 & $\mathbf{1 , 0 2 3}$ \\
\hline Humboldt & 7 & 2 & $\mathbf{9}$ \\
\hline Kern & 2,498 & 53 & $\mathbf{2 , 5 5 1}$ \\
\hline Kings & 134 & 5 & $\mathbf{1 3 9}$ \\
\hline Los Angeles & 3,368 & 82 & $\mathbf{3 , 4 5 0}$ \\
\hline Marin & 1,911 & 61 & $\mathbf{1 , 9 7 2}$ \\
\hline Merced & 48 & 2 & $\mathbf{5 0}$ \\
\hline Monterey & 10 & 2 & $\mathbf{1 2}$ \\
\hline Napa & 36 & 1 & $\mathbf{3 7}$ \\
\hline Orange & 1,581 & 44 & $\mathbf{1 , 6 2 5}$ \\
\hline Placer & 11,832 & 159 & $\mathbf{1 1 , 9 9 1}$ \\
\hline Riverside & 4,262 & 87 & $\mathbf{4 , 3 4 9}$ \\
\hline Sacramento & 10,928 & 483 & $\mathbf{1 1 , 4 1 1}$ \\
\hline San Bernardino & 2,138 & 50 & $\mathbf{2 , 1 8 8}$ \\
\hline San Diego & 1,083 & 30 & $\mathbf{1 , 1 1 3}$ \\
\hline San Francisco & 407 & 16 & $\mathbf{4 2 3}$ \\
\hline San Joaquin & 1,807 & 20 & $\mathbf{1 , 8 2 7}$ \\
\hline San Luis Obispo & 232 & 1 & $\mathbf{2 3 3}$ \\
\hline San Mateo & 2,647 & 92 & $\mathbf{2 , 7 3 9}$ \\
\hline Santa Barbara & 224 & 7 & $\mathbf{2 3 1}$ \\
\hline Santa Clara & 6,127 & 157 & $\mathbf{6 , 2 8 4}$ \\
\hline Santa Cruz & 90 & 1 & $\mathbf{9 1}$ \\
\hline Solano & 2,413 & 39 & $\mathbf{2 , 4 5 2}$ \\
\hline Sonoma & 1,246 & 32 & $\mathbf{1 , 2 7 8}$ \\
\hline Tulare & 774 & 14 & $\mathbf{7 8 8}$ \\
\hline Ventura & 1,643 & 42 & $\mathbf{1 , 6 8 5}$ \\
\hline Yolo & 16 & 1 & $\mathbf{1 7}$ \\
\hline Yuba & 860 & 23 & $\mathbf{8 8 3}$ \\
\hline & & & $\mathbf{7 0 , 4 2 5}$ \\
\hline
\end{tabular}


Figure 1: Map of Frequencies of PV Homes by California County

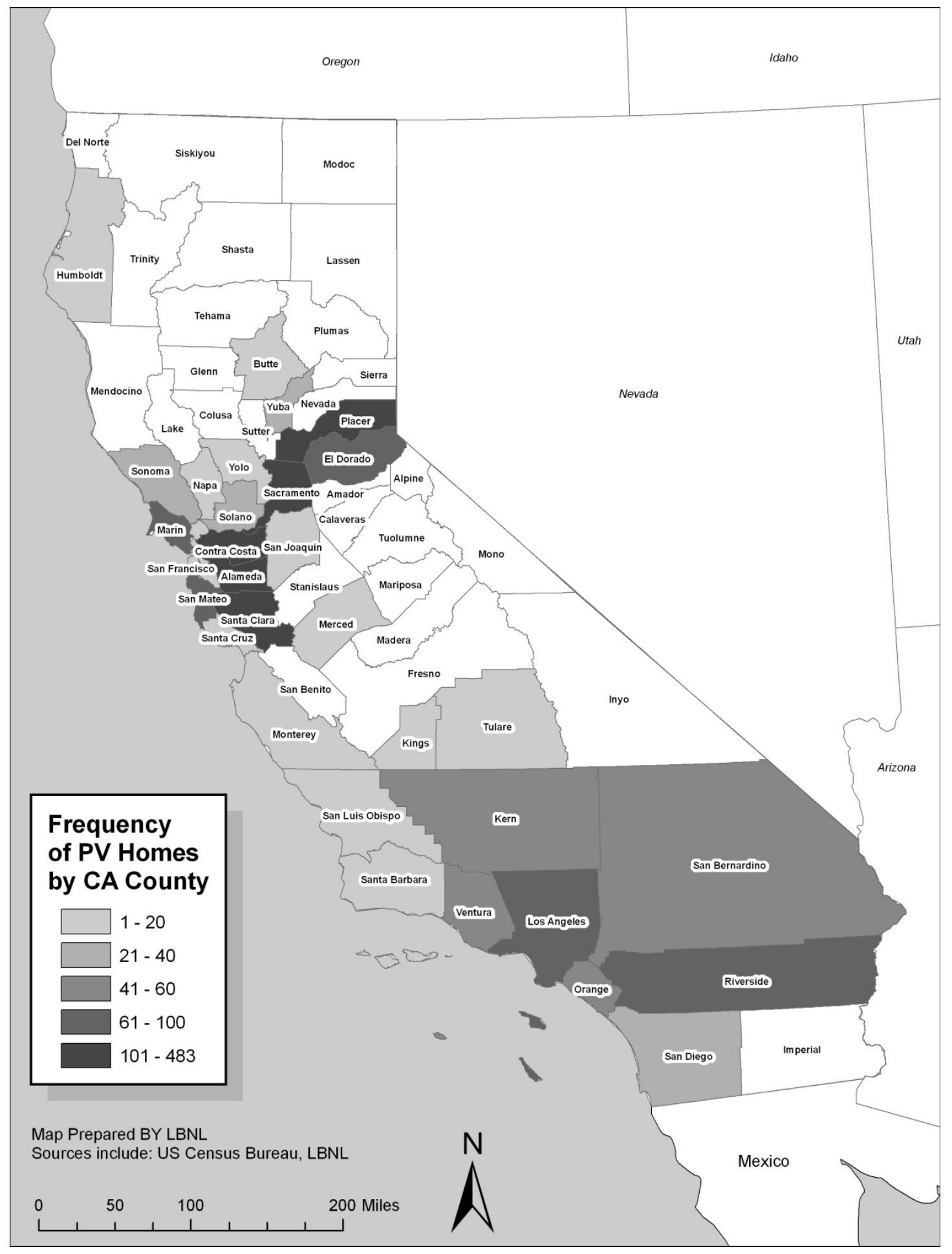


Table 5: Frequency Summary by Home Type, Utility and Sale Year

\begin{tabular}{|c|c|c|c|}
\hline Home Type * & Non-PV & PV & Total \\
\hline New Home & 26,938 & 935 & 27,873 \\
\hline Existing Home & 43,487 & 897 & 44,384 \\
\hline Utility ** & Non-PV & PV & Total \\
\hline $\begin{array}{l}\text { Pacific Gas \& Electric } \\
\text { (PG\&E) }\end{array}$ & 36,137 & 1,019 & 37,156 \\
\hline $\begin{array}{l}\text { Southern California } \\
\text { Edison (SCE) }\end{array}$ & 14,502 & 337 & 14,839 \\
\hline $\begin{array}{l}\text { San Diego Gas \& } \\
\text { Electric (SDG\&E) }\end{array}$ & 8,191 & 35 & 8,226 \\
\hline $\begin{array}{l}\text { Sacramento Municipal } \\
\text { Utility District (SMUD) }\end{array}$ & 11,393 & 498 & 11,891 \\
\hline Other & 202 & 5 & 207 \\
\hline Sale Year & Non-PV & PV & Total \\
\hline 1999 & 110 & 0 & 110 \\
\hline 2000 & 379 & 1 & 380 \\
\hline 2001 & 1,335 & 10 & 1,345 \\
\hline 2002 & 6,278 & 37 & 6,315 \\
\hline 2003 & 8,783 & 63 & 8,846 \\
\hline 2004 & 10,888 & 153 & 11,041 \\
\hline 2005 & 10,678 & 168 & 10,846 \\
\hline 2006 & 9,072 & 173 & 9,245 \\
\hline 2007 & 8,794 & 472 & 9,266 \\
\hline 2008 & 9,490 & 642 & 10,132 \\
\hline 2009 & 4,618 & 175 & 4,793 \\
\hline
\end{tabular}

* A portion of the PV homes could not be classified as either new or existing and therefore are not included in these totals

** Non-PV utility frequencies were estimated by mapping block groups to utility service areas, and then attributing the utility to all homes that were located in the block group 


\section{Methods and Statistical Models}

\subsection{Methodological Overview}

The data, as outlined above, not only show increased sales values and appreciation for PV homes (in 2009 \$) over non-PV homes, but also important differences between PV and non-PV homes as regards other home, site, neighborhood and market characteristics that could, potentially, be driving these differences in value and appreciation. A total of 21 empirical model specifications, with a high reliance on the hedonic pricing model, are used in this paper to disentangle these potentially competing influences in order to determine whether and to what degree PV homes sell for a premium.

The basic theory behind the hedonic pricing model starts with the concept that a house can be thought of as a bundle of characteristics. When a price is agreed upon between a buyer and seller there is an implicit understanding that those characteristics have value. When data from a number of sales transactions are available, the average individual marginal contribution to the sales price of each characteristic can be estimated with a hedonic regression model (Rosen, 1974; Freeman, 1979). This relationship takes the basic form:

Sales price $=f$ (home and site, neighborhood, and market characteristics)

"Home and site characteristics" might include, but are not limited to, the number of square feet of living area, the size of the parcel of land, and the presence of a PV system. "Neighborhood" characteristics might include such variables as the crime rate, the quality of the local school district, and the distance to the central business district. Finally, "market characteristics" might include, but are not limited to, temporal effects such as housing market inflation/deflation.

A variant of the hedonic model is a repeat sales model, which holds constant many of the characteristics discussed above, and compares inflation adjusted selling prices of homes that have sold twice, both before a condition exists (e.g., before a PV system is installed on the home) and after the condition exists (e.g., after a PV system is installed on the home), and across PV 
and non-PV homes. This repeat sales model, in the form used in this paper, is referred to as a difference-in-difference (DD) model, and is discussed in more detail later.

To test for the impact of PV systems on residential selling prices, a series of "base" hedonic models, a "base" difference-in-difference model, a series of robustness models, and two "other" models are estimated for this research. ${ }^{17}$ As discussed later, these models are used to test for fixed (whether the home has a PV system) and continuous (the size of the PV system) effects using the full dataset of PV homes. They are also used to test for any differences that exist between new and existing PV homes and between homes with PV systems of different ages, and to test for the possibility of non-linear returns to scale based on the size of the PV system or the home itself. Before describing these models in more detail, however, a summary of the variables to be included in the models is provided.

\subsection{Variables Used in Models}

In each base model, be it hedonic or difference-in-difference, four similar sets of parameters are estimated, namely coefficients on the variables of interest and coefficients for three sets of controls that include home and site characteristics, neighborhood (census block group) fixed effects, and temporal (year and quarter) fixed effects. The variables of interest are the focus of the research, and include such variables as whether the home has a PV system installed or not, the size of the PV system, and interactions between these two variables and others, such as the size of the home or the age of the PV system. To accurately measure these variables of interest (and their interactions) other potentially confounding variables need to be controlled for in the models. The base models differ in their specification and testing of the variables of interest, as discussed later, but use the same three sets of controls.

The first of these sets of control variables accounts for differences across the dataset in home and site-specific characteristics, including the age of the home (linear and squared), the total square feet of living area, and the relative elevation of the home (in feet) to other homes in the block group; the latter variable serves as a proxy for "scenic vista," a value-influencing characteristic

\footnotetext{
${ }^{17}$ As will be discussed later, each of the "base" models is coupled with a set of two or three robustness models. The "other" models are presented without "robustness" models.
} 
(see e.g., Hoen et al., 2009). ${ }^{18}$ Additionally, the size of the property in acres was entered into the model in spline form to account for different valuations of less than one acre and greater than one acre.

The second set of controls, the geographic fixed effects variables, includes dummy variables that control for aggregated "neighborhood” influences, which, in our case, are census block groups. ${ }^{19}$ A census block group generally contains between 200 and 1,000 households, ${ }^{20}$ and is delineated to never cross boundaries of states, counties, or census tracts, and therefore, in our analysis, serves as a proxy for "neighborhood.” To be usable, each block group had to contain at least one PV home and one non-PV home. The estimated coefficients for this group of variables capture the combined effects of school districts, tax rates, crime, distance to central business district and other block group specific characteristics. This approach greatly simplifies the estimation of the model relative to determining these individual characteristics for each home, but interpreting the resulting coefficients can be difficult because of the myriad of influences captured by the variables. Because block groups are fairly small geographically, spatial autocorrelation ${ }^{21}$ is also, to some degree, dealt with through the inclusion of these variables.

Finally, the third set of controls, the temporal fixed effect variables, includes dummy variables for each quarter of the study period to control for any inaccuracies in the housing inflation adjustment that was used. A housing inflation index is used to adjust the sales prices throughout the study period to 2009 prices at a zip code level across as many as three price tiers. Although

\footnotetext{
${ }^{18}$ Other home and site characteristics were also tested, such as the condition of the home, the number of bathrooms, the number of fireplaces, and if the home had a garage and/or a pool. Because these home and site characteristics were not available for all home transactions (and thus reduced the sample of homes available), did not add substantial explanatory power to the model, and did not affect the results substantively, they were not included in the model results presented in this paper.

${ }^{19}$ For a portion of the dataset, a common subdivision name was identified, which, arguably, serves as a better proxy for neighborhood than block group. Unfortunately, not all homes fell within a subdivision. Nonetheless, a separate combined subdivision-block group fixed effect was tested and will be discussed later.

${ }^{20}$ Census block groups generally contain between 600 and 3,000 people, and the median household size in California is roughly 3.

${ }^{21}$ Spatial Autocorrelation - a correlation between neighbors' selling prices - can produce unstable coefficient estimates, yielding unreliable significance tests in hedonic models if not accounted for. One reason for this spatial autocorrelation is omitted variables, such as neighborhood characteristics (e.g., distance to the central business district), which affect all properties within the same area similarly. Having micro-spatial controls, such as block groups or subdivisions, helps control for such autocorrelation.
} 
this adjustment is expected to greatly improve the model - relative to using just a temporal fixed effect with an unadjusted price - it is also assumed that because of the volatility of the housing market, the index may not capture price changes perfectly and therefore the model is enhanced with the additional inclusion of these quarterly controls. ${ }^{22}$

\subsection{Fixed and Continuous Effect Hedonic Models}

The analysis begins with the most basic model comparing prices of all of the PV homes in the sample (whether new or existing) to non-PV homes across the full dataset. As is common in the literature (Malpezzi, 2003; Sirmans et al., 2005b; Simons and Saginor, 2006), a semi-log functional form of the hedonic pricing model is used where the dependent variable, the (natural log of) sales price (P), is measured in zip code-specific inflation-adjusted (2009) dollars. To determine if an average-sized PV system has an effect on the sale price of PV homes (i.e., a fixed effect) we estimate the following base fixed effect model:

$$
\ln \left(\mathrm{P}_{\mathrm{itk}}\right)=\alpha+\beta_{1}\left(\mathrm{~T}_{\mathrm{t}}\right)+\beta_{2}\left(\mathrm{~N}_{\mathrm{k}}\right)+\sum_{\mathrm{a}} \beta_{3}\left(\mathrm{X}_{\mathrm{i}}\right)+\beta_{4}\left(\mathrm{PV}_{\mathrm{i}}\right)+\varepsilon_{\mathrm{itk}}
$$

where

$\mathrm{P}_{i t k}$ represents the inflation adjusted sale price for transaction $i$, in quarter $t$, in block group $k$, $\alpha$ is the constant or intercept across the full sample,

$\mathrm{T}_{t}$ is the quarter in which transaction $i$ occurred,

$\mathrm{N}_{k}$ is the census block group in which transaction $i$ occurred,

$\mathrm{X}_{i}$ is a vector of $a$ home characteristics for transaction $i$ (e.g., acres, square feet, age, etc.),

$\mathrm{PV}_{i}$ is a fixed effect variable indicating a PV system is installed on the home in transaction $i$, $\beta_{1}$ is a parameter estimate for the quarter in which transaction $i$ occurred,

$\beta_{2}$ is a parameter estimate for the census block group in which transaction $i$ occurred,

$\beta_{3}$ is a vector of parameter estimates for home characteristics $a$,

$\beta_{4}$ is a parameter estimate for the PV fixed effects variable, and

$\varepsilon_{i t k}$ is a random disturbance term for transaction $i$,in quarter $t$, in block group $k$.

\footnotetext{
${ }^{22}$ A number of models were tested both with and without these temporal controls and with a variety of different temporal controls (e.g., monthly) and temporal/spatial controls (e.g., quarter and tract interactions). The quarterly dummy variables were the most parsimonious, and none of the other approaches impacted the results substantively.
} 
The parameter estimate of primary interest in this model is $\beta_{4}$, which represents the marginal percentage change in sale price with the addition of an average sized PV system. If differences in selling prices exist between PV and non-PV homes, we would expect the coefficient to be positive and statistically significant.

An alternative to equation (1) is to interact the PV fixed effect variable $\left(\mathrm{PV}_{\mathrm{i}}\right)$ with the size (in $\mathrm{kW})$ of the PV system as installed on the home at the time of sale (SIZE $\left.\mathrm{E}_{\mathrm{i}}\right)$, thereby producing an estimate for the differences in sales prices as a function of size of the PV system. This base continuous effect model takes the form:

$$
\ln \left(\mathrm{P}_{\mathrm{itk}}\right)=\alpha+\beta_{1}\left(\mathrm{~T}_{\mathrm{t}}\right)+\beta_{2}\left(\mathrm{~N}_{\mathrm{k}}\right)+\sum_{\mathrm{a}} \beta_{3}\left(\mathrm{X}_{\mathrm{i}}\right)+\beta_{4}\left(\mathrm{PV}_{\mathrm{i}} \cdot \mathrm{SIZE}_{\mathrm{i}}\right)+\varepsilon_{\mathrm{itk}}
$$

where

$\mathrm{SIZE}_{i}$ is a continuous variable for the size (in $\mathrm{kW}$ ) of the PV system installed on the home prior to transaction $i$,

$\beta_{4}$ is a parameter estimate for the percentage change in sale price for each additional $\mathrm{kW}$ added to a PV system, and all other terms are as were defined for equation (1).

If differences in selling prices exist between PV and non-PV homes, we would expect the coefficient to be positive and statistically significant, indicating that for each additional kilowatt added to the PV system the sale price increases by $\beta_{4}$ (in \% terms).

This continuous effect specification may be preferable to the PV fixed effect model because one would expect that the impact of PV systems on residential selling prices would be based, at least partially, on the size of the system, as size is related to energy bill savings. ${ }^{23}$ Moreover, this specification allows for a direct estimate of any PV home sales premium in dollars per watt (\$/watt), which is the form in which other estimates - namely average net installed costs - are reported. With the previous fixed effects specification, a \$/watt estimate can still be derived, but

\footnotetext{
${ }^{23}$ Ideally, the energy bill savings associated with individual PV systems could be entered into the model directly, but these data were not available. Moreover, estimating the savings accurately on a system-by-system basis was not possible because of the myriad of different rate structures in California, the idiosyncratic nature of energy use at the household level, and variations in PV system designs and orientations.
} 
not directly. Therefore, where possible in this paper, greater emphasis is placed on the continuous effect specification than on the fixed effect estimation.

As mentioned earlier, for each base model we explore a number of different robustness models to better understand if and to what degree the results are unbiased. In the present research, two areas of bias are of particular concern: omitted variable bias and sample selection bias.

The omitted variables that are of specific concern are any that might be correlated with the presence of $\mathrm{PV}$, and that might affect sales prices. An example is energy efficiency (EE) improvements, which might be installed contemporaneously with a PV energy system. If many homes with PV have EE improvements, whereas the comparable non-PV homes do not, then estimates for the effects of PV on selling prices might be inclusive of EE effects and, therefore, may be inappropriately high. Any other value-influencing home improvements (e.g., kitchen remodels, new roofs, etc.), if correlated with the presence of PV, could similarly bias the results if not carefully addressed.

With respect to selection bias, the concern is that the distribution of homes that have installed PV may be different from the broad sample of homes on which PV is not installed. If both sets of homes are assumed to have similar distributions but are, in point of fact, dissimilar due to selection, then the estimates for the effects of PV on the selling price could be inclusive of these underlying differences but attributed to the existence of PV, thereby also potentially biasing the results.

To mitigate the issue of omitted variable bias, one robustness model uses the same data sample as the base model but a different model specification. Specifically, a combined subdivisionblock group fixed effect variable can be substituted, where available, in place of the block group fixed effect variable as an alternative proxy for "neighborhood." Potentially omitted variables are likely to be more similar between PV and non-PV homes at the subdivision level than at the 
block group level, and therefore this model may more-effectively control for such omitted variables. ${ }^{24}$

To mitigate the issue of selection bias, one robustness model uses the same model specification as the base model but with an alternative (subset) of the data sample. Specifically, instead of using the full dataset with equations (1) and (2), a "coarsened exact matched" dataset is used (King et al., 2010). ${ }^{25}$ This matching procedure results in a reduced sample of homes to analyze, but the PV and non-PV homes that remain in the matched sample are statistically equal on their covariates after the matching process (e.g., PV homes within a block group are matched with non-PV homes such that both groups are similar in the number of bathrooms, date of sale, etc.). As a result, biases related to selection are minimized.

Finally, specific to equation (2), a robustness model to mitigate both omitted variable and selection bias is constructed in which the sample is restricted to include only PV homes (in place of the full sample of PV and non-PV homes). Because this model does not include non-PV “comparable” homes, sales prices of PV homes are "compared” against each other based on the size of the PV systems, while controlling for the differences in the home via the controlling characteristics (e.g., square feet of living space). PV system size effects are therefore estimated without the use of non-PV homes, providing an important comparison to the base models, while also directly addressing any concerns about the inherent differences between PV and non-PV homes (e.g., whether energy efficient upgrades were made contemporaneously with the PV) and therefore omitted variable and sample selection bias.

\footnotetext{
${ }^{24}$ Subdivisions are often geographically smaller than block groups, and therefore more accurately control for geographical influences such as distance to central business district. Moreover, homes in the same subdivision are often built at similar times using similar materials and therefore serve as a control for a variety of house specific characteristics that are not controlled for elsewhere in the model. For example, all homes in a subdivision will often be built using the same building code with similar appliances being installed, both of which might control for the underlying energy efficiency (EE) characteristics of the home. For homes not situated in a subdivision, the block group delineation was used, and therefore these fixed effects are referred to as "combined subdivision-block group" delineations.

${ }^{25}$ The procedure used, as described in the referenced paper, is coarsened exact matching (cem) in Stata, available at: http://ideas.repec.org/c/boc/bocode/s457127.html. The matching procedure creates statistically matched sets of PV and non-PV homes in each block group, based on a set of covariates, which, for this research, include the number of square feet, acres, and baths, as well as the age of the home, its elevation, and the date at which it sold. Because this matching process excludes non-PV homes that are without a statistically similar PV match (and vice versa), a large percentage of homes (approximately $80 \%$ non-PV and 20\% PV) are not included in the resulting dataset.
} 


\subsection{New and Existing Home Models}

Although equations (1) and (2) are used to estimate whether a PV system, on average, effects selling prices across the entire data sample, they do not allow one to distinguish any such effects as a function of house type, specifically whether the home is new or existing. As discussed earlier, new homes with PV might have different premiums than existing homes. To try to tease out these possible differences, two base hedonic models are estimated using equation (2), one with only new homes and the other with only existing homes. ${ }^{26}$ Comparing the coefficient of the variable of interest $\left(\beta_{4}\right)$ between these two models allows for an assessment of the relative size of the impact of PV systems across the two home types.

Additionally, two sets of robustness models that were discussed earlier are also applied to the new and existing home models, one using the coarsened exact matched datasets and the other using the combined subdivision-block group delineations. These models test the robustness of the results for selection and omitted variable bias, respectively. Although it is discussed separately as a base model in the following subsection, the difference-in-difference model, using repeat sales of existing homes, also doubly serves as a robustness test to the existing homes base model.

\subsubsection{Difference-in-Difference Models}

One classic alternative to estimating a hedonic model, as briefly discussed earlier, is to estimate a difference-in-difference (DD) model (Wooldridge, 2009). This model (see Table 1) uses a set of homes that have sold twice, both with and without PV, and provides estimates of the effect of adding PV to a subset of those homes as of the second sale ("DD” as noted in Table 1), while simultaneously accounting for both the inherent differences in the PV and non-PV groups and the trend in housing prices between the first and second sales of non-PV homes. Repeat sales models of this type are particularly effective in controlling for selection and certain types of

\footnotetext{
${ }^{26}$ New and existing homes were determined in an iterative process. For PV homes, the type of home was often specified by the data provider. It was also discovered that virtually all of the new PV homes (as specified by the PV data providers) had ages, at the time of sale, between negative one and two years, inclusive, whereas the existing PV homes (as specified by the PV data providers) had ages greater than two years in virtually every case. The small percentage (3\%) of PV homes that did not fit these criteria were excluded from the models. For non-PV homes, no data specifying the home type were available, therefore, groupings were created following the age at sale criteria used for PV homes (e.g., ages between negative one and two years apply to new non-PV homes).
} 
omitted variable bias. In the former case, any underlying difference in home prices between PV and non-PV homes prior to the addition of PV is controlled for. In the latter case, PV and nonPV homes are assumed to have undergone mostly similar changes (e.g., home improvements) between sales. Any changes to the home that are coincident with the installation of a PV system (or the PV system household), on the other hand, are not directly controlled for in this model, though there is reason to believe that any such remaining influences are not imposing substantial bias in the present study. ${ }^{27}$

The set of PV homes that are used in the DD model are, by default, existing homes (i.e., the home was not new when the PV system was installed). Estimates derived from this model, therefore, apply to - while also serving as a robustness tests for - the existing home models as specified above.

Table 6: Difference-in-Difference Description

\begin{tabular}{|l|c|c|l||}
\hline & Pre PV & Post PV & \multicolumn{1}{|c|}{ Difference } \\
\hline PV Homes & $\mathrm{PV}_{1}$ & $\mathrm{PV}_{2}$ & $\Delta \mathrm{PV}=\mathrm{PV}_{2}-\mathrm{PV}_{1}$ \\
\hline Non-PV Homes & $\mathrm{NPV}_{1}$ & $\mathrm{NPV}_{2}$ & $\Delta \mathrm{NPV}=\mathrm{NPV}_{2}-\mathrm{NPV}_{1}$ \\
\hline & & & $\mathrm{DD}=\Delta \mathrm{PV}-\Delta \mathrm{NPV}$ \\
\hline \multicolumn{1}{|l|}{ and 2 denote time periods } & & \\
\hline
\end{tabular}

The base DD model is estimated as follows:

$$
\ln \left(\mathrm{P}_{\mathrm{itk}}\right)=\alpha+\beta_{1}\left(\mathrm{~T}_{\mathrm{t}}\right)+\beta_{2}\left(\mathrm{~N}_{\mathrm{k}}\right)+\sum_{\mathrm{a}} \beta_{3}\left(\mathrm{X}_{\mathrm{i}}\right)+\beta_{4}\left(\mathrm{PVH}_{\mathrm{i}}\right)+\beta_{5}\left(\mathrm{SALE}_{\mathrm{i}}\right)+\beta_{6}\left(\mathrm{PVS}_{\mathrm{i}}\right)+\varepsilon_{\mathrm{itk}}
$$

where

$\mathrm{PVH}_{i}$ is a fixed effect variable indicating if a PV system is or will be installed on the home in transaction $i$,

\footnotetext{
${ }^{27}$ Support for this assumption comes from two sources. Although surveys (e.g., CPUC, 2010) indicate that PV homeowners install energy efficient "measures" with greater frequency than non-PV homeowners, the differences are relatively small and largely focus on lighting and appliances. The former is not expected to substantially impact sales prices, while the latter could. The surveys also indicate that PV homeowners tend to install other larger EE measures, such as building shell, water heating and cooling improvements, with greater frequency than non-PV homes. Additionally, it might also be hypothesized that PV homeowners may be more-likely to have newer roofs (perhaps installed at the time of PV installation). Dastrop et al. (2010), however, investigated whether home improvements that might require a permit affect PV home sales premium estimates, and found they did not. It should be noted that the PV Only model, discussed previously, directly addresses the concern of omitted variable bias for this analysis.
} 
SALE $2_{i}$ is a fixed effect variable indicating if transaction $i$ is the second of the two sales, $\mathrm{PVS}_{i}$ is a fixed effect variable (an interaction between $\mathrm{PVH}_{\mathrm{i}}$ and $\mathrm{SALE} 2_{\mathrm{i}}$ ) indicating if transaction $i$ is both the second of the two sales and contained a PV system at the time of sale,

$\alpha$ is the constant or intercept across the full sample,

$\beta_{4}$ is a parameter estimate for homes that have or will have PV installed (i.e., from Table 6 "PV $1-\mathrm{NPV}_{1}$ "),

$\beta_{5}$ is a parameter estimate if transaction $i$ occurred as of the second sale (i.e., " $\Delta$ NPV"), $\beta_{6}$ is a parameter estimate if transaction $i$ occurred as of the second sale and the home contained PV (i.e., " $\Delta \mathrm{PV}-\Delta \mathrm{NPV}$ " or "DD"), and all other terms are as were defined for equation (1).

The coefficient of interest is $\beta_{6}$, which represents the percentage change in sale price, as expressed in 2009 dollars, when PV is added to the home, after accounting for the differences between PV and non-PV homes $\left(\beta_{4}\right)$ and the differences between the initial sale and the second sale of non-PV homes $\left(\beta_{5}\right)$. If differences in selling prices exist between PV and non-PV homes, we would expect the coefficient to be positive and statistically significant. ${ }^{28}$

To further attempt to mitigate the potential for omitted variable bias, two robustness models are estimated for the base DD model: one with the combined subdivision-block group delineations and a second with a limitation applied on the number of days between the first and second sale. ${ }^{29}$ The first robustness model is similar to the one discussed earlier. The second robustness model accounts for the fact that the home characteristics used (in all models) reflect the most recent home assessment, and therefore do not necessarily reflect the characteristics at the time of the sale. Especially worrisome are the first sales in the DD model, which can be as much as 20 years before the second sale. To test if our results are biased because of these older sales - and the

\footnotetext{
${ }^{28}$ This is the classic model form derived from a quasi-experiment, where the installation of PV is the treatment. An alternative specification would look at the incremental effect of PV system size holding the starting differences between PV and non-PV homes as well as the time-trend in non-PV homes constant. This model form was not evaluated in the current analysis effort, but could be considered grounds for future research in this area.

${ }^{29}$ Ideally a matched dataset could be utilized, for reasons described earlier, but because the matching procedure severely limited the size of the dataset, the resulting dataset was too small to be useful.
} 
large periods between sales - an additional data screen is applied in which the difference between the two sale dates is limited to five years. ${ }^{30}$

\subsection{Age of the PV System for Existing Homes Hedonic Models}

The age of the PV system at the time of home sale could affect the sales price premium for existing homes (PV systems on new homes are, by definition, also new). This might occur because older PV systems have a shorter expected remaining life and may become somewhat less efficient with age (and therefore deliver a lower net present value of bill savings), but also because older PV systems will have generated more energy bill savings for the home seller and the seller may therefore more-willingly accept a lower price. Together, these factors suggest that premiums for older PV systems on existing homes would be expected to be lower than for newer systems. In order to test this directly the following base model is estimated:

$$
\ln \left(P_{i t k}\right)=\alpha+\beta_{1}\left(T_{t}\right)+\beta_{2}\left(N_{k}\right)+\sum_{a} \beta_{3}\left(X_{i}\right)+\beta_{4}\left(P V_{i} \cdot S I Z E_{i} \cdot A G E_{i}\right)+\varepsilon_{i t k}
$$

where

$\mathrm{AGE}_{i}$ is a categorical variable for three groups of PV system age as of the time of sale of the home: 1) less than or equal to one year old; 2) between 2 and 4 years old; and, 3) five or more years old.

Therefore, $\beta_{4}$ is a vector of parameter estimates for the percentage change in sales price for each additional kW added to a PV system for each of the three PV system age groups, and all other terms are as are defined for equation (2). The assumption is that the coefficients for $\beta_{4}$ will be decreasing - indicating they are valued less - as the age of the PV systems decrease. The sample used for this model is the same as for the existing home model defined previously.

Additionally, two sets of robustness models are explored, one using the coarsened exact matched dataset and the other using the combined subdivision-block group delineations, to test the robustness of the results for selection and omitted variable bias, respectively.

\footnotetext{
${ }^{30}$ As was discussed earlier, a screen for this eventuality (using adjaar) is incorporated in our data cleaning. This test therefore serves as an additional check of robustness of the results.
} 


\subsection{Returns to Scale Hedonic Models}

As discussed earlier, it is not unreasonable to expect that any increases in the selling prices of PV homes may be non-linear with PV system size. In equation (2), it was assumed that estimated price differences were based on a continuous linear relationship with the size of the system. To explore the possibility of a non-linear relationship among the full sample of homes in the dataset, the following model is estimated: ${ }^{31}$

$$
\ln \left(P_{i t k}\right)=\alpha+\beta_{1}\left(T_{t}\right)+\beta_{2}\left(N_{k}\right)+\sum_{a} \beta_{3}\left(X_{i}\right)+\beta_{4}\left(P V_{i} \cdot S I Z E_{i}\right)+\beta_{5}\left(P V_{i} \cdot S I Z E_{i} \cdot S I Z E_{i}\right)+\varepsilon_{i t k}
$$

where

$\beta_{5}$ is a parameter estimate for the percentage change in sales price for each additional $\mathrm{kW}$ added to a PV system squared, and all other terms are as are defined for equation (2).

A negative statistically significant coefficient $\left(\beta_{5}\right)$ would indicate decreasing returns to scale for larger PV systems, while a positive coefficient would indicate the opposite.

Somewhat analogously, as was discussed previously, premiums for PV systems may be related to the size of the home. ${ }^{32}$ To test this directly using the full dataset, the following model is estimated:

$$
\begin{aligned}
\ln \left(P_{i t k}\right)= & \alpha+\beta_{1}\left(T_{t}\right)+\beta_{2}\left(N_{k}\right)+\sum_{a} \beta_{3}\left(X_{i}\right)+\beta_{4}\left(S Q F T_{i}\right)+\beta_{5}\left(P V_{i} \cdot S I Z E_{i}\right)+ \\
& \beta_{6}\left(P V_{i} \cdot S I Z E_{i} \cdot S Q F T_{i}\right)+\varepsilon_{i t k}
\end{aligned}
$$

where

$\mathrm{SQFT}_{\mathrm{i}}$ is a continuous variable for the number of square feet for the home in transaction $i,{ }^{33}$

$\beta_{4}$ is a parameter estimate for the percentage change in sale price for each additional 1000 square feet added to the home,

\footnotetext{
${ }^{31}$ Neither this nor the following model is coupled with robustness models in this paper.

${ }^{32} \mathrm{PV}$ system size is also somewhat correlated with house size as a result of the tendency for increasing energy use and larger roof areas on larger homes. If this correlation was particularly strong then coefficient estimates could be imprecise. The correlation between PV house size and PV system size in the full sample of our data, however, is rather weak, at only 0.14. Clearly, many factors other than house size impact the sizing of PV systems.

${ }^{33}$ In all of the previous models the number of square feet is contained in the vector of characteristics represented by $\mathrm{X}_{\mathrm{i}}$, but in this model it is separated out for clarity.
} 
$\beta_{5}$ is a parameter estimate for the percentage change in sale price for each additional $\mathrm{kW}$ added to a PV system,

$\beta_{6}$ is a parameter estimate for the percentage change in sale price for each additional 1000 square feet added to PV homes, assuming the size of the PV system does not change, and all other terms are as were defined for equation (2).

A negative statistically significant coefficient for $\beta_{6}$ would indicate decreasing returns to scale for PV systems as homes increase in size. Alternatively, a positive and statistically significant coefficient would indicate increasing returns to scale for PV systems installed on larger homes. 


\subsection{Model Summary}

To summarize, the entire set of 21 estimated models discussed herein is shown in Table 7 . The following definitions of terms, all of which were discussed earlier, are relevant for interpreting the models listed in the table, and therefore are briefly reviewed again. All "base" models are coupled with a set of "robustness" models (as noted by a capital "R" in the model number). The “Other” (returns to scale) models are presented alone. Models 1 - 4 and 6 - 8 use the hedonic pricing model, whereas Model 5 is based on the difference-in-difference (DD) model. "Fixed” (versus “continuous”) means that the PV variable is entered into the regression as a zero-one dichotomous variable (for Models 1-1Rb and 5-5Rb), whereas “continuous” (for all other models) means that the model estimates the impact of an increase in PV system size on residential selling prices. Base Models 1, 2, 7 and 8 use the full dataset, while Models 4 and 6 are restricted to existing homes, Model 3 to new homes, and Model 5 to the repeat sales dataset. The "matched" models use the smaller dataset of coarsened exact matched (PV and non-PV) homes. "Base" models estimate neighborhood fixed effects at the census block group level, whereas the "subdivision" models estimate neighborhood fixed effects at the combined subdivision-block group level.

Table 7: Summary of Models

\begin{tabular}{|l|l|c|c|c|l|l|}
\hline $\begin{array}{c}\text { Model } \\
\text { Number }\end{array}$ & Model Name & $\begin{array}{c}\text { Base } \\
\text { Model }\end{array}$ & $\begin{array}{c}\text { Robustness } \\
\text { Model }\end{array}$ & $\begin{array}{l}\text { Other } \\
\text { Models }\end{array}$ & $\begin{array}{l}\text { Neighborhood } \\
\text { Fixed Effects }\end{array}$ \\
\hline $\mathbf{1}$ & Fixed - Base & $\mathbf{X}$ & & & Full & Block Group \\
\hline $\mathbf{1 R a}$ & Fixed - Matched & & $\mathbf{X}$ & & Full Matched & Block Group \\
\hline $\mathbf{1 R b}$ & Fixed - Subdivision & & $\mathbf{X}$ & & Full & Subdivision/Block Group \\
\hline $\mathbf{2}$ & Continuous - Base & $\mathbf{X}$ & & & Full & Block Group \\
\hline $\mathbf{2 R a}$ & Continuous - Matched & & $\mathbf{X}$ & & Full Matched & Block Group \\
\hline $\mathbf{2 R b}$ & Continuous - Subdivision & & $\mathbf{X}$ & & Full & Subdivision/Block Group \\
\hline $\mathbf{2 R c}$ & Continuous - PV Only & & $\mathbf{X}$ & & PV Only & Block Group \\
\hline $\mathbf{3}$ & New Homes - Base & $\mathbf{X}$ & & & New & Block Group \\
\hline $\mathbf{3 R a}$ & New - Matched & & $\mathbf{X}$ & & New - Matched & Block Group \\
\hline $\mathbf{3 R b}$ & New - Subdivision & & $\mathbf{X}$ & & New & Subdivision/Block Group \\
\hline $\mathbf{4}$ & Existing Homes - Base & $\mathbf{X}$ & & & Existing & Block Group \\
\hline $\mathbf{4 R a}$ & Existing - Matched & & $\mathbf{X}$ & & Existing - Matched & Block Group \\
\hline $\mathbf{4 R b}$ & Existing - Subdivision & & $\mathbf{X}$ & & Existing & Subdivision/Block Group \\
\hline $\mathbf{5}$ & Difference-in-Difference (DD) - Base & $\mathbf{X}$ & & & Repeat Sales & Block Group \\
\hline $\mathbf{5 R a}$ & Difference-in-Difference (DD) - Subdivision & & $\mathbf{X}$ & & Repeat Sales & Subdivision/Block Group \\
\hline $\mathbf{5 R b}$ & Difference-in-Difference (DD) - Sddif $<5$ Years & & $\mathbf{X}$ & & Repeat Sales w/ sddif $<5$ & Block Group \\
\hline $\mathbf{6}$ & Age of System - Base & $\mathbf{X}$ & & & Existing & Block Group \\
\hline $\mathbf{6 R a}$ & Age of System - Matched & & $\mathbf{X}$ & & Existing - Matched & Block Group \\
\hline $\mathbf{6 R b}$ & Age of System - Subdivision & & $\mathbf{X}$ & & Existing & Subdivision/Block Group \\
\hline $\mathbf{7}$ & Returns to Scale - Size & & & $\mathbf{X}$ & Full & Block Group \\
\hline $\mathbf{8}$ & Returns to Scale - Square Feet & & Block Group \\
\hline
\end{tabular}




\section{Estimation Results}

Estimation results for all 21 models (as defined in Table 7) are presented in Tables 8-11, with the salient results on the impacts of PV on homes sales prices summarized in Figures 2-4. ${ }^{34,35}$ The adjusted $\mathrm{R}^{2}$ for all models is high, ranging from 0.93 to 0.95 , which is notable because the dataset spanned a period of unusual volatility in the housing market. The model performance reflects, in part, the ability of the inflation index and temporal fixed effects variables to adequately control for market conditions. ${ }^{36}$

Moreover, the sign and magnitude of the home and site control variables are consistent with $a$ priori expectations, are largely stable across all models, and are statistically significant at the $1 \%$ level in most models. ${ }^{37}$ Each additional 1000 square feet of living area added to a home is estimated to add between $19 \%$ and $26 \%$ to its value, while the first acre adds approximately $40 \%$ to its value with each additional acre adding approximately $1.5 \%$. For each year a home ages, it is estimated that approximately $0.2 \%$ of its value is lost, yet at 60 years, age becomes an asset with homes older than that estimated to garner premiums for each additional year in age. Finally, for each additional 100 feet above the median elevation of the other homes in the block group, a home's value is estimated to increase by approximately $0.3 \%$. These results can be benchmarked to other research. Specifically, Sirmans et al. (2005a; 2005b) conducted a meta-analysis of 64 hedonic pricing studies carried out in multiple locations in the U.S. during multiple time periods, and investigated similar characteristics as included in the models presented here, except for relative elevation. As a group, each of the home and site characteristic estimates in the present

\footnotetext{
${ }^{34}$ For simplicity, this paper does not present the results for the quarter and block group (nor combined subdivisionblock group) fixed effects, which consist of more than 900 coefficients. These are available upon request from the authors.

${ }^{35}$ All models were estimated with Stata SE Version 11.1 using the "areg” procedure with White's correction for standard errors (White, 1980). It should also be noted that all Durbin-Watson (Durbin and Watson, 1951) test statistics were within the acceptable range (Gujarati, 2003), there was little multicollinearity associated with the variables of interest, and all results were robust to the removal of any cases with a Cook's Distance greater than $4 / n$ (Cook, 1977) and/or standardized residuals greater than four.

${ }^{36}$ As mentioned in footnote 22, a variety of approaches were tested to control for market conditions, such as spatial temporal fixed effects (e.g., census block / year quarter) both with and without adjusted sale prices. The models presented here were the most parsimonious. As importantly, the results were robust to the various specifications, which, in turn, provides additional confidence that the effects presented are not biased by the fluctuating market conditions that have impacted the housing market for some years.

${ }^{37}$ In some models, where there is little variation between the cases on the covariate (e.g., acres), the results are nonsignificant at the $10 \%$ level.
} 
study differ from the mean Sirmans et al. estimates by no more than one half of one standard deviation.

In summary, these results suggest that the hedonic and repeat sales models estimated here are effectively capturing many of the drivers to home sales prices in California, and therefore increasing confidence that those same models can be used to accurately capture any PV effects that may exist.

\subsection{Fixed and Continuous Effect Hedonic Model Results}

The results from the base hedonic models (equations 1 and 2) are shown in Table 8 as Models 1 and 2, respectively. These models estimate the differences across the full dataset between PV and non-PV homes, with Model 1 estimating this difference as a fixed effect, and Model 2 estimating the difference as a continuous effect for each additional kilowatt (kW) of PV added. Also shown in the table are the results from the robustness tests using the coarsened exact matching procedure and the combined subdivision-block group delineations, as shown as Models 1Ra and 1Rb for PV fixed effect models and Models 2Ra and 2Rb for continuous effect variables. Finally, the model that derives marginal impact estimates from only PV homes is shown in the table as Model 2Rc.

Across all seven of these models (Models 1 - 2Rc), regardless of the specification, the variables of interest of PV and SIZE are positive and significant at the $10 \%$ level, with six out of seven estimates being significant at the 1\% level. Where a PV fixed effect is estimated, the coefficient can be interpreted as the percentage increase in the sales price of a PV home over the mean nonPV home sales price in 2009 dollars based on an average sized PV system. By dividing the monetary value of this increase by the number of watts for the average sized system, this premium can be converted to 2009 dollars per watt (\$/watt). For example, for base Model 1, multiplying the mean non-PV house value of $\$ 480,862$ by 0.036 and dividing by 3120 watts, yields a premium of $\$ 5.5 /$ watt (see bottom of Table 8 ). Where SIZE, a continuous PV effect, is used, the coefficients reflect the percentage increase in selling prices in 2009 dollars for each additional $\mathrm{kW}$ added to the PV system. Therefore, to convert the SIZE coefficient to \$/watt, the mean house value for non-PV homes is multiplied by the coefficient and divided by 1000 . For 
example, for base Model 2, \$480,862 is multiplied by 0.012 and divided by 1000 , resulting in an estimate of $\$ 5.8 /$ watt. $^{38}$

As summarized in Figure 2, these base model results for the impact of PV on residential selling prices are consistent with those estimated after controlling for subdivision fixed effects (\$5.4/watt and \$5.6/watt for fixed and continuous effects, respectively), differing by no more than \$0.2/watt. On the other hand, the estimated PV premiums derived from the coarsened exact matched dataset are noticeably smaller, decreasing by 20 to 30\%, and ranging from $\$ 3.9 /$ watt to \$4.8/watt for fixed and continuous effects, respectively. Alternatively, the PV only Model 2Rc estimates a higher $\$ /$ watt continuous effect of $\$ 6.4 /$ watt, although that estimate is statistically significant at a lower $10 \%$ level. This estimate, because it is derived from PV homes only, corroborates that any changes to the home that are coincident with the installation of the PV (e.g., energy efficient upgrades) are not influencing results dramatically.

Figure 2: Fixed and Continuous Effect Base Model Results with Robustness Tests

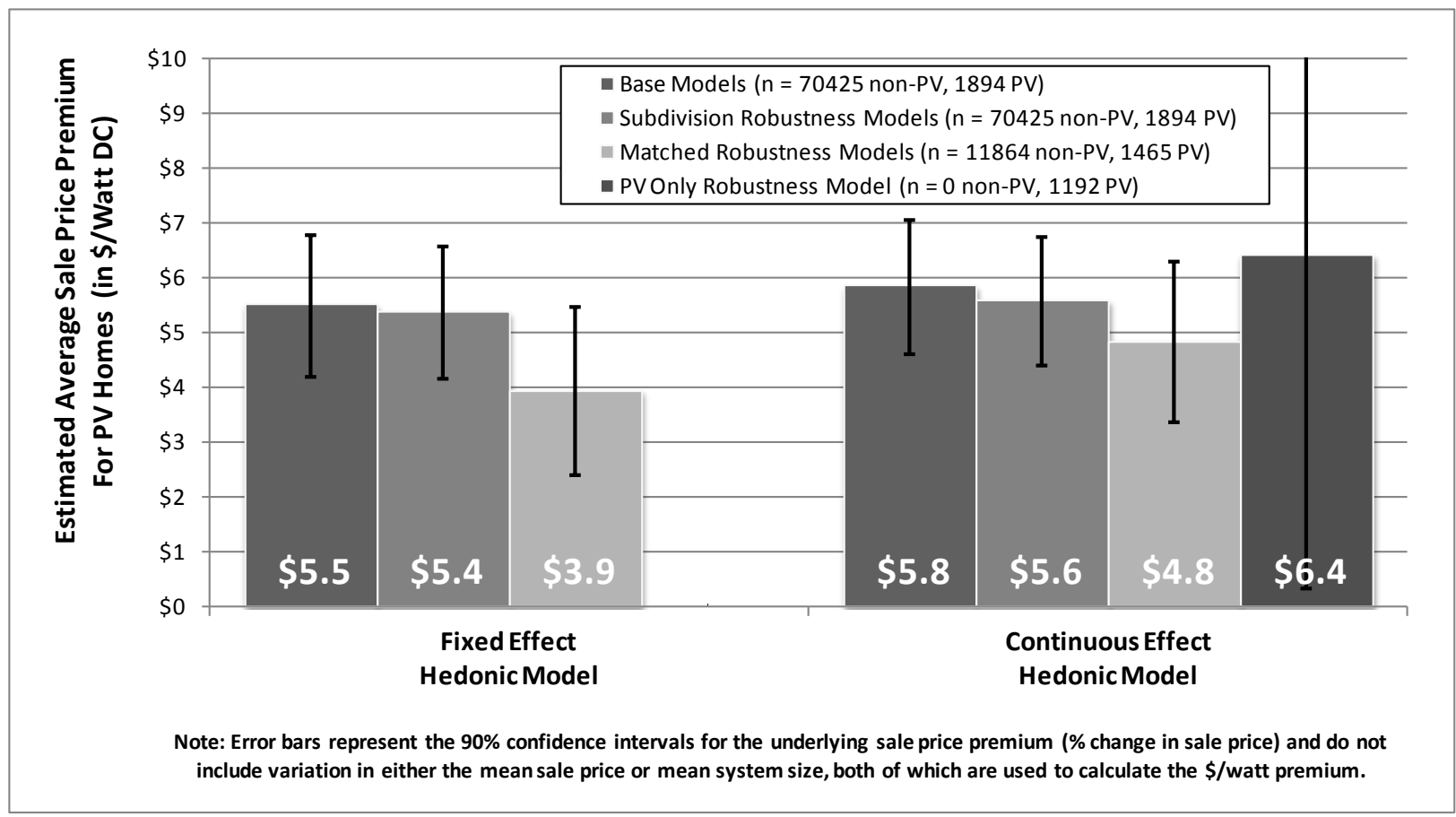

\footnotetext{
${ }^{38}$ To be exact, the conversion is a bit more complicated. For example, for the fixed effect model the conversion is actually $(\operatorname{EXP}(\mathrm{LN}(480,862)+0.036)-480,862) / 3.12 / 1000$, but the differences are de minimis, and therefore are not used herein.
} 
Though results among these seven models differ to some degree, the results are consistent in finding a premium for PV homes over non-PV homes in California, which varies from \$3.9 to $\$ 6.4 /$ watt on average, depending on the model specification. These sale price premiums are very much in line with, if not slightly above, the historical mean net installed costs (i.e., the average installed cost of a system, after deducting available state and federal incentives) of residential PV systems in California of approximately \$5/watt from 2001 through 2009 (Barbose et al., 2010), which, as discussed earlier, may be reasonable given that both buyers and sellers might use this cost as a partial basis to value a home. ${ }^{39}$

Additionally, the one other hedonic analysis of PV selling price premiums (which used reasonably similar models as those employed here but a different dataset, concentrating only on homes in the San Diego metropolitan area) found a similar result (Dastrop et al., 2010). In their analysis of 279 homes that sold with PV systems installed in San Diego (our model only contained 35 homes from this area ${ }^{40}$ - See Table 5), Dastrop et al. estimated an average increase in selling price of $\$ 14,069$, which, when divided by their mean PV system size of $3.2 \mathrm{~kW}$, implies an effect of $\$ 4.4 /$ watt. $^{41}$

\footnotetext{
${ }^{39}$ Although not investigated here, one possible reason for sales price premiums that are above net installed costs is that buyers of PV homes may in some cases price in the opportunity cost of avoiding having to do the PV installation themselves, which might be perceived as complex. Moreover, a PV system installation that occurs after the purchase of the home would likely be financed outside the first mortgage and would therefore loose valuable finance and tax benefits, thereby making the purchase of a PV home potentially more attractive that installing a PV system later, even if at the same cost.

${ }^{40}$ Though we identified a higher number of PV homes that sold in the San Diego metropolitan area in our dataset, the home and site characteristics provided to us from the real estate data provider did not contain information on the year of the sale and therefore were not usable for the purpose of our analysis.

${ }^{41}$ In a different model, Dastrop et al. (2010) estimated an effect size of \$2.4/watt but, for reasons not addressed here, this estimate is not believed to be as robust.
} 
Table 8: Fixed and Continuous Base Hedonic Model Results with Robustness Tests

\begin{tabular}{|c|c|c|c|c|c|c|c|}
\hline & \multicolumn{3}{|c|}{ Fixed } & \multicolumn{4}{|c|}{ Continuous } \\
\hline & Base & Robustness & Robustness & Base & Robustness & Robustness & Robustness \\
\hline & & Matched & Subdivision & & Matched & Subdivision & PV Only \\
\hline & Model 1 & Model 1Ra & Model 1Rb & Model 2 & Model 2Ra & Model 2Rb & Model 2Rc \\
\hline \multirow[t]{2}{*}{ pv } & $0.036 * * *$ & $0.024 * * *$ & $0.035 * * *$ & & & & \\
\hline & $(0.005)$ & $(0.006)$ & $(0.005)$ & & & & \\
\hline \multirow[t]{2}{*}{ size } & & & & $0.012 * * *$ & $0.010 * * *$ & $0.012 * * *$ & $0.013^{*}$ \\
\hline & & & & $(0.002)$ & $(0.002)$ & $(0.001)$ & (0.008) \\
\hline \multirow[t]{2}{*}{ sqft_1000 } & $0.253 * * *$ & $0.205 * * *$ & $0.250 * * *$ & $0.253^{* * *}$ & $0.205^{* * *}$ & $0.250 * * *$ & $0.224 * * *$ \\
\hline & $(0.001)$ & $(0.006)$ & $(0.001)$ & $(0.001)$ & $(0.006)$ & $(0.001)$ & $(0.010)$ \\
\hline \multirow[t]{2}{*}{ It1acre } & $0.417 * * *$ & $0.514^{* * *}$ & $0.414^{* * *}$ & $0.416^{* * *}$ & $0.510 * * *$ & $0.413^{* * *}$ & $0.441^{* * *}$ \\
\hline & $(0.009)$ & $(0.040)$ & $(0.010)$ & $(0.009)$ & $(0.040)$ & $(0.010)$ & $(0.066)$ \\
\hline \multirow[t]{2}{*}{ acre } & $0.016^{* * *}$ & 0.013 & $0.015^{* * *}$ & $0.016^{* * *}$ & 0.013 & $0.015^{* * *}$ & -0.002 \\
\hline & $(0.002)$ & $(0.011)$ & $(0.003)$ & $(0.002)$ & $(0.010)$ & $(0.003)$ & $(0.012)$ \\
\hline \multirow[t]{2}{*}{ ages 2} & $-0.004 * * *$ & $-0.006 * * *$ & $-0.004 * * *$ & $-0.004 * * *$ & $-0.006 * * *$ & $-0.004 * * *$ & $-0.008 * * *$ \\
\hline & $(0.0002)$ & $(0.0012)$ & $(0.0002)$ & $(0.0002)$ & $(0.0012)$ & $(0.0002)$ & $(0.0030)$ \\
\hline \multirow[t]{2}{*}{ ages $2 s q r$} & $0.00003 * * *$ & $0.00004 * * *$ & $0.00003 * * *$ & $0.00003^{* * *}$ & $0.00004 * * *$ & $0.00003^{* * *}$ & $0.00004 * * *$ \\
\hline & $(0.000003)$ & $(0.000012)$ & $(0.000003)$ & $(0.000003)$ & $(0.000012)$ & $(0.000003)$ & $(0.000033)$ \\
\hline \multirow[t]{2}{*}{ bgre_100 } & $0.003^{* * *}$ & $0.015^{* * *}$ & $0.003^{* * *}$ & $0.003^{* * *}$ & $0.015^{* * *}$ & $0.003 * * *$ & $0.013^{* * *}$ \\
\hline & $(0.001)$ & $(0.004)$ & $(0.001)$ & $(0.001)$ & $(0.004)$ & $(0.001)$ & $(0.005)$ \\
\hline \multirow[t]{2}{*}{ intercept } & $12.703 * * *$ & $12.961^{* * *}$ & $12.710^{* * *}$ & $12.702^{* * *}$ & $12.957 * * *$ & $12.710^{* * *}$ & $12.842 * * *$ \\
\hline & $(0.010)$ & $(0.044)$ & $(0.012)$ & $(0.010)$ & $(0.043)$ & $(0.012)$ & $(0.073)$ \\
\hline
\end{tabular}

\begin{tabular}{|c|c|c|c|c|c|c|c|}
\hline \multicolumn{8}{|c|}{ Numbers in parenthesis are standard errors, ${ }^{* * *} p<0.01,{ }^{* *} p<0.05,{ }^{*} p<0.1$} \\
\hline \multicolumn{8}{|c|}{ Results for subdivision, block group, and quarterly fixed effect variables are not } \\
\hline \multicolumn{8}{|c|}{ reported here, but are available upon request from the authors } \\
\hline Total $\mathbf{n}$ & 72,319 & 13,329 & 72,319 & 72,319 & 13,329 & 72,319 & 1,192 \\
\hline Adiusted $\mathrm{R}^{2}$ & 0.93 & 0.95 & 0.94 & 0.93 & 0.95 & 0.94 & 0.93 \\
\hline n (pvhomes) & 1,894 & 1,465 & 1,894 & 1,894 & 1,465 & 1,894 & 1,192 \\
\hline Mean non-pv asp2 & $\$ 480,862$ & $\$ 480,533$ & $\$ 480,862$ & $\$ 480,862$ & $\$ 480,533$ & $\$ \quad 480,862$ & \$ 475,811 \\
\hline Mean size (kW) & 3.1 & 3.0 & 3.1 & 3.1 & 3.0 & 3.1 & 2.7 \\
\hline Estimated \$/Watt & 5.5 & 3.9 & 5.4 & 5.8 & 4.8 & 5.6 & 6.4 \\
\hline
\end{tabular}

\subsection{New and Existing Home Model Results}

Turning from the full dataset to one specific to the home type, we estimate continuous effects models for new and existing homes (see equation (2)). These results are shown in Table 9, with Model 3 the base model for new homes and Model 4 the base model for existing homes. Also 
shown are the results from the robustness tests using the coarsened exact matching procedure and the combined subdivision-block group delineations, as Models 3Ra and 3Rb, respectively, for new homes, and as Models 4Ra and 4Rb, respectively, for existing homes.

The coefficient of interest, SIZE, is statistically significant at or below the $10 \%$ level in all of the new home models and at the $1 \%$ level in all of the existing home models. Estimates for the average \$/watt increase in selling prices as a result of PV systems (as summarized in Figure 3, which also includes the results presented earlier for all homes, Models 2, 2Ra, and 2Rb) for new homes are quite stable, ranging from \$2.3 to \$2.6/watt. In comparison, for PV sold with existing homes, not only are the selling price impacts found to be higher, but their range across the three models is somewhat greater, ranging from $\$ 6.4$ to $\$ 7.7 /$ watt.

\section{Figure 3: New and Existing Home Base Model Results with Robustness Tests}

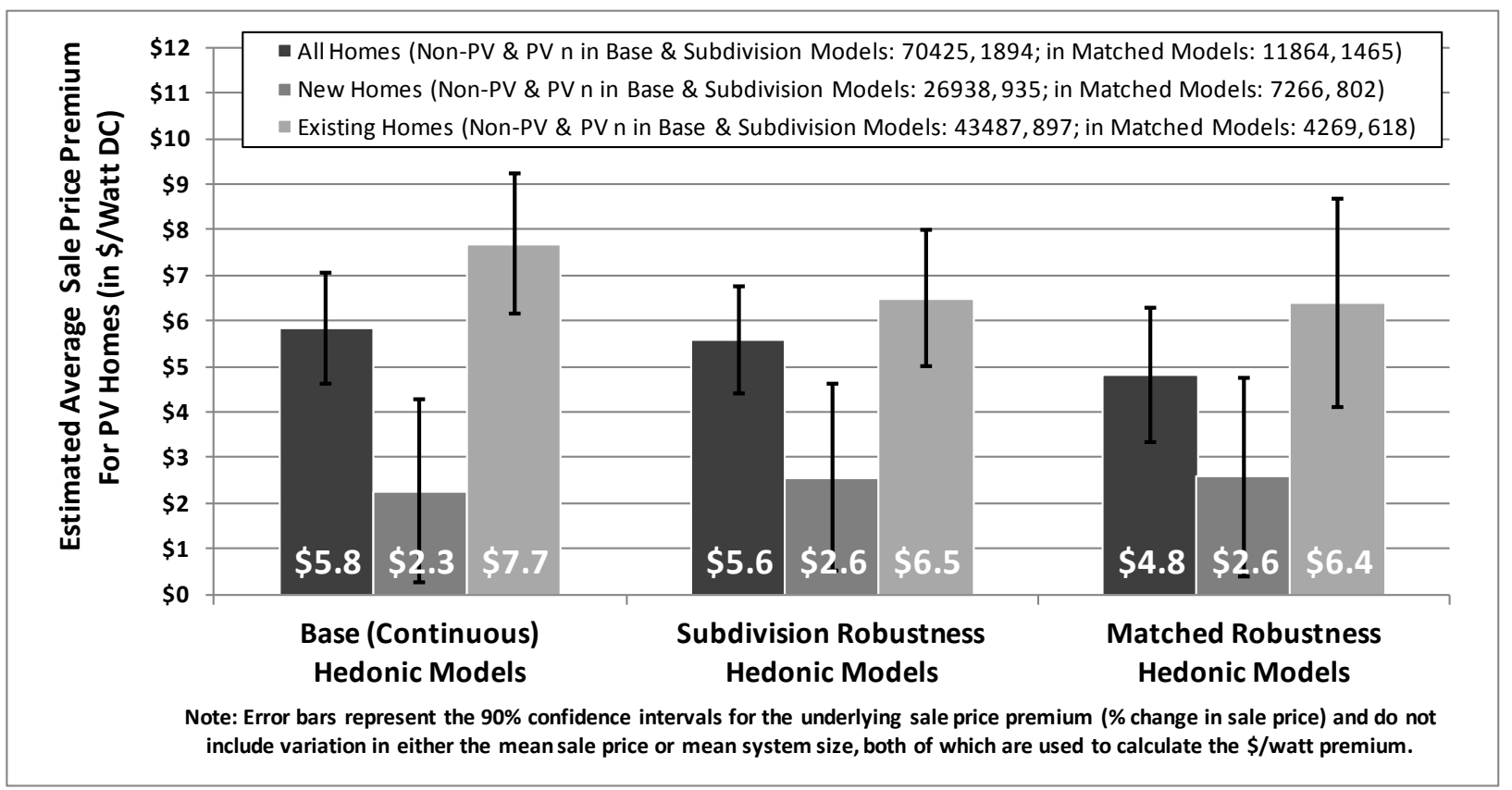

Though the reasons for the apparent discrepancy in selling price impacts between new and existing homes are unclear, and warrant future research, they might be explained, in part, by the difference in average net installed costs, which, from 2007 to 2009, were approximately \$5.2/watt for existing homes and \$4.2/watt for new homes in California (derived from the dataset used for Barbose et al., 2010). The gap in net installed costs between new and existing homes is 
not wide enough to fully account for these findings, however, with the model estimates for PV selling price premiums below the average net installed costs for new homes and above the average net installed costs for existing homes. ${ }^{42}$

Several alternative explanations for the disparity between new and existing home premiums exist. As discussed previously, there is evidence that builders of new homes might discount premiums for PV if, in exchange, PV systems provide other benefits for new home developers, such as greater product differentiation and increased the sales velocity, thus decreasing overall carrying costs (Dakin et al., 2008; SunPower, 2008). Further, sellers of new homes with PV might be reluctant to aggressively increase home sale prices for installed PV systems because of the burgeoning state of the market for PV homes and concern that more aggressive pricing could even slow home sales. Additionally, because many builders of new homes found that offering PV as an option, rather than a standard feature, posed a set of difficulties (Farhar et al., 2004b; Dakin et al., 2008), it has been relatively common in past years for PV to be sold as a standard feature on homes (Dakin et al., 2008). This potentially affects the valuation of PV systems for two reasons. First, because sales agents for the new PV homes have sometimes been found to either not be well versed in the specifics of PV and felt that selling a PV system was a new sales pitch (Farhar et al., 2004b) or to have combined the discussion of PV with a set of other energy features (Dakin et al., 2008), up-selling the full value of the PV system as a standard product feature might not have been possible. Secondly, the average sales price of new homes in our dataset is lower than the average sales price of existing homes: to the extent that PV is considered a luxury good, it may be somewhat less-highly valued for the buyers of these homes.

These downward influences for new homes are potentially contrasted with analogous upward influences for existing homes. Related, buyers of existing homes with PV may - to a greater degree than buyers of the less expensive new homes in our sample - be self selected towards those who place particular value on a PV home, and therefore value the addition more. Finally, in contrast to new home sellers, who might not be familiar with the intricacies and benefits of the

\footnotetext{
${ }^{42}$ A small number of "affordable homes" ( $\left.n=7\right)$ are included in the new PV homes subset, which, as a group, appear to have a slight downward yet inconsequential effect on the overall sales premium results, and therefore were not investigated further herein. If the number of affordable homes with PV was significant in future research, those effects would best be controlled for directly.
} 
PV system, existing home sellers are likely to be very familiar with the particulars of the system and its benefits, and therefore might be able to "up-sell” it more effectively.

These possible influences, in combination, may explain the difference in average PV premium between new and existing homes. The present analysis did not seek to disentangle or evaluate these specific drivers, however, leaving that important effort for future research.

Table 9: New and Existing Home Base Hedonic Model Results with Robustness Tests

\begin{tabular}{|c|c|c|c|c|c|c|}
\hline & \multicolumn{3}{|c|}{ New Homes } & \multicolumn{3}{|c|}{ Existing Homes } \\
\hline & Base & Robustness & Robustness & Base & Robustnes & Robustness \\
\hline & & Matched & Subdivision & & Matched & Subdivision \\
\hline & Model 3 & Model 3Ra & Model 3Rb & Model 4 & Model 4Ra & Model 4Rb \\
\hline \multirow[t]{2}{*}{ size } & $0.006^{*}$ & $0.006^{*}$ & $0.006 * *$ & $0.014 * * *$ & $0.011 * * *$ & $0.012 * * *$ \\
\hline & $(0.003)$ & $(0.003)$ & $(0.003)$ & $(0.002)$ & $(0.002)$ & $(0.002)$ \\
\hline \multirow[t]{2}{*}{ sqft_1000 } & $0.247 * * *$ & $0.190 * * *$ & $0.250 * * *$ & $0.256 * * *$ & $0.238 * * *$ & $0.251 * * *$ \\
\hline & $(0.002)$ & $(0.006)$ & $(0.002)$ & $(0.002)$ & $(0.015)$ & $(0.002)$ \\
\hline \multirow[t]{2}{*}{ lt1acre } & $0.536 * * *$ & $0.279 * * *$ & $0.517 * * *$ & $0.373 * * *$ & $0.426 * * *$ & $0.376 * * *$ \\
\hline & $(0.019)$ & $(0.073)$ & $(0.024)$ & $(0.010)$ & $(0.046)$ & $(0.012)$ \\
\hline \multirow[t]{2}{*}{ acre } & -0.007 & $0.338 * * *$ & $-0.009 *$ & $0.019 * * *$ & 0.011 & $0.017 * * *$ \\
\hline & $(0.005)$ & $(0.027)$ & $(0.005)$ & $(0.002)$ & $(0.011)$ & $(0.003)$ \\
\hline \multirow[t]{2}{*}{ ages 2} & -0.010 & $0.081 * * *$ & $-0.010^{*}$ & $-0.005^{* * *}$ & $-0.006 * * *$ & $-0.005^{* * *}$ \\
\hline & $(0.006)$ & $(0.017)$ & $(0.006)$ & $(0.000)$ & $(0.002)$ & $(0.000)$ \\
\hline \multirow[t]{2}{*}{$\operatorname{ages} 2 s q r$} & $0.00768 * * *$ & $-0.02443 * * *$ & $0.00715^{* * *}$ & $0.00004 * * *$ & $0.00004^{* * *}$ & $0.00004^{* * *}$ \\
\hline & $(0.001676)$ & $(0.004407)$ & (0.001604) & $(0.000003)$ & $(0.000014)$ & $(0.000004)$ \\
\hline \multirow[t]{2}{*}{ bgre_100 } & $0.008 * * *$ & $0.027 * * *$ & $0.007 * * *$ & 0.002 & -0.002 & 0.002 \\
\hline & $(0.001)$ & $(0.003)$ & $(0.001)$ & $(0.001)$ & $(0.009)$ & $(0.001)$ \\
\hline \multirow[t]{2}{*}{ intercept } & $12.651^{* * *}$ & $12.585 * * *$ & $12.627 * * *$ & $12.820 * * *$ & $13.023 * * *$ & $12.833 * * *$ \\
\hline & $(0.022)$ & $(0.066)$ & $(0.025)$ & $(0.013)$ & $(0.077)$ & $(0.014)$ \\
\hline
\end{tabular}

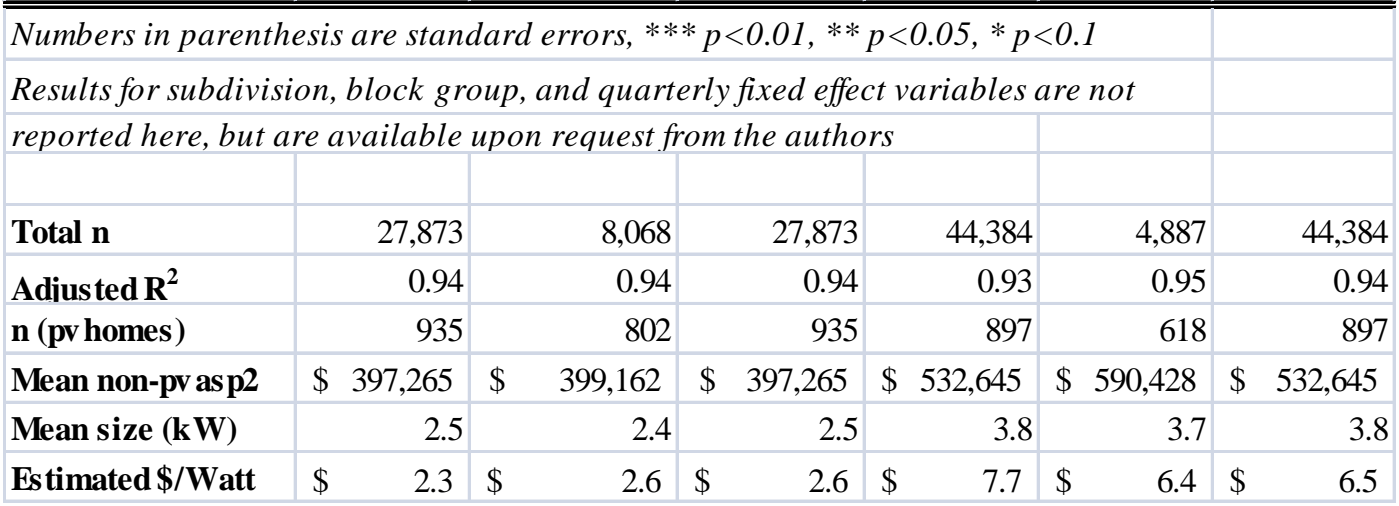




\subsubsection{Difference-in-Difference Model Results}

Delving deeper into PV system impacts on existing homes, Table 10 (and Figure 4) shows the results of the base Difference-in-Difference Model 5 as well as results from the two robustness tests (all of which can be compared to Models 4, 4Ra, and 4rb above, as is done in Figure 4). As a reminder, one robustness model limited the differences in sales dates between the first and second sales to five years (Model 5Rb), and the other robustness model used the combined subdivision-block group delineations as fixed effects variables (Model 5Rc). The variables of interest are PVH, SALE2 and especially PVS.

PVH estimates the difference in the first sale prices of homes that will have PV installed (as of the second sale date) relative to non-PV homes. The three models are consistent in their estimates, showing approximately a 2\% premium for "future" PV homes, though only two of these estimates are statistically significant, and then only at the $10 \%$ level. Regardless, this finding suggests that PV homes tend to sell for somewhat more even before the installation of $\mathrm{PV}$, presumably as a result of other amenities that are correlated with the (ultimate) installation of PV (such as, potentially, energy efficiency features). SALE2 estimates the price appreciation trend between the first and second sales for all homes. The coefficient for this variable is significant at the $1 \%$ level, and is fairly stable across the models, indicating a clear general trend of price increases, over and above inflation adjustments, of approximately $2 \%$ to $2.5 \%$ between the first and second sales.

Finally, and most importantly, homes with PV systems installed on them as of the second sale after controlling for any inherent differences in first sale prices (PVH) and any trend between the first and second sales (SALE2) - show statistically significant sale price premiums of approximately 5 to $6 \%$. These premiums equate to an increase in selling prices of approximately \$6/watt for existing homes, closely reflecting the results presented earlier for the hedonic models in Table 9 and Figure 3. For comparison purposes, both sets of results are presented in Figure 4.

The premium for existing PV homes as estimated in the DD Models 5, 5Ra, and 5Rb and both robustness tests for the hedonic model (using the "matched" and "subdivision" datasets, Models 4Ra and 4Rb respectively) are consistently between $\$ 6$ and \$6.5/watt and are in line with - 
though slightly higher than - the mean net installed costs of PV on existing homes in California of approximately \$5.2/watt from 2007 through 2009. The base hedonic existing home model, on the other hand, estimates a higher premium of $\$ 7.7 /$ watt. One possible explanation for this inconsistency is that the two robustness tests for the hedonic model and the various difference-indifference models are less likely to be influenced by either selection or omitted variable bias than the base hedonic model. Regardless of the absolute magnitude, a sizable premium for existing PV homes over that garnered by new PV homes is clearly evident in these and the earlier results.

\section{Figure 4: Existing Home Hedonic and Difference-in-Difference Model Results with}

\section{Robustness Tests}

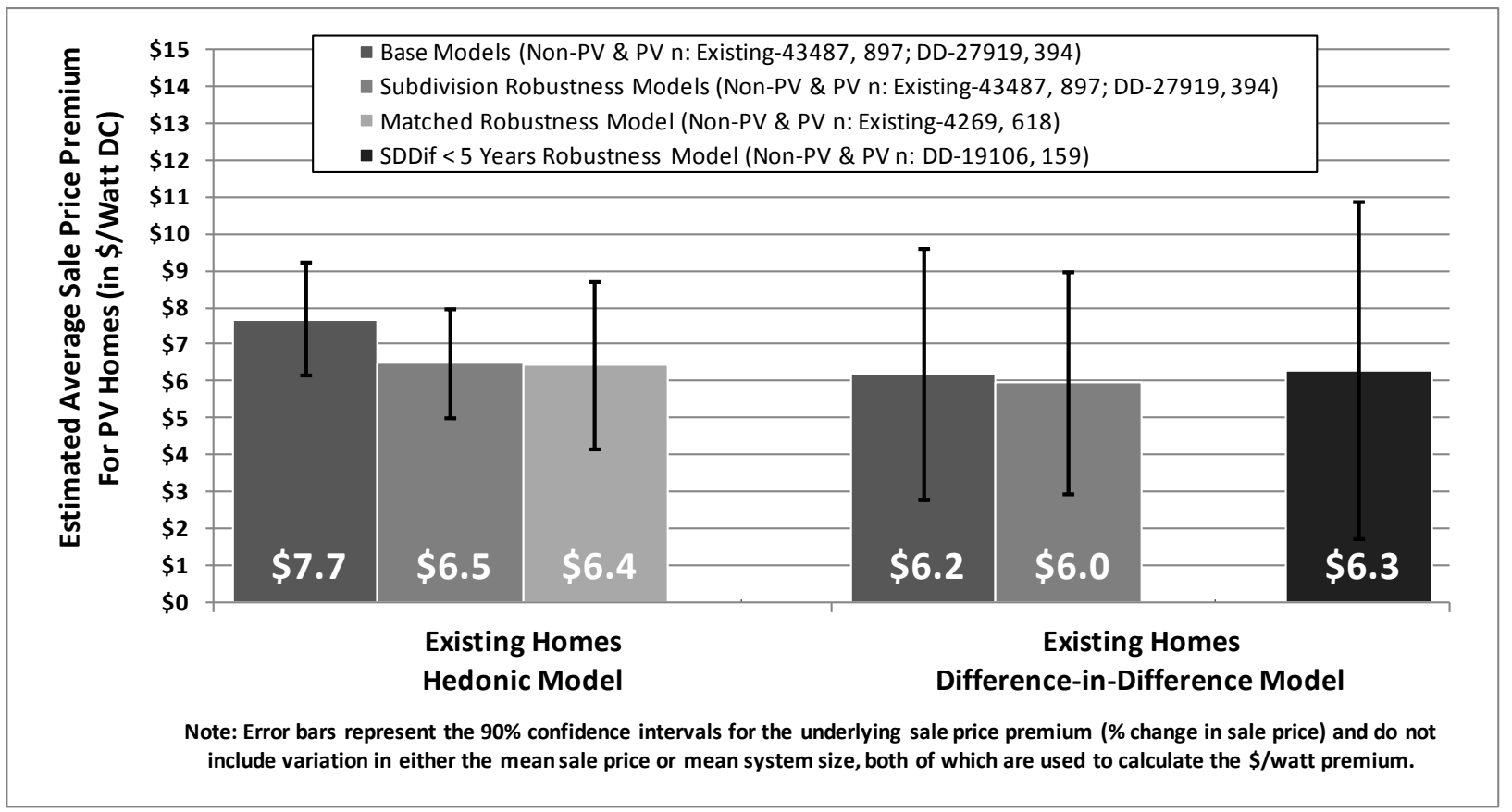


Table 10: Difference-in-Difference Model Results

\begin{tabular}{|c|c|c|c|}
\hline & \multicolumn{3}{|c|}{ Difference-in-Difference } \\
\hline & Base & Robustness & Robustness \\
\hline & \multirow[b]{2}{*}{ Model 5} & Subdivision & Sddif $<5$ \\
\hline & & Model 5Ra & Model 5Rb \\
\hline \multirow[t]{2}{*}{ pvh } & $0.022 *$ & 0.024 & $0.022 *$ \\
\hline & $(0.013)$ & $(0.021)$ & $(0.012)$ \\
\hline \multirow[t]{2}{*}{ sale2 } & $0.023^{* * *}$ & $0.026 * * *$ & $0.019 * * *$ \\
\hline & $(0.002)$ & $(0.002)$ & $(0.002)$ \\
\hline \multirow[t]{2}{*}{ pvs } & $0.051^{* * *}$ & $0.061^{* *}$ & $0.049 * * *$ \\
\hline & $(0.017)$ & $(0.027)$ & $(0.015)$ \\
\hline \multirow[t]{2}{*}{ sqft_1000 } & $0.255^{* * *}$ & $0.256^{* * *}$ & $0.251^{* * *}$ \\
\hline & $(0.002)$ & $(0.002)$ & $(0.002)$ \\
\hline It1acre & $0.374 * * *$ & $0.385^{* * *}$ & $0.377 * * *$ \\
\hline & $(0.011)$ & $(0.013)$ & $(0.012)$ \\
\hline acre & $0.012^{* * *}$ & $0.009 * *$ & $0.011^{* * *}$ \\
\hline & $(0.003)$ & $(0.004)$ & $(0.003)$ \\
\hline age & $-0.005^{* * *}$ & $-0.005^{* * *}$ & $-0.005^{* * *}$ \\
\hline & $(0.0002)$ & $(0.0003)$ & $(0.0003)$ \\
\hline agesqr & $0.00004^{* * *}$ & $0.00004 * * *$ & $0.00004 * * *$ \\
\hline & $(0.000003)$ & $(0.000003)$ & $(0.000003)$ \\
\hline bgre_100 & $0.002 *$ & 0.000 & 0.001 \\
\hline & $(0.001)$ & $(0.001)$ & $(0.001)$ \\
\hline intercept & $12.677 * * *$ & $12.594 * * *$ & $12.694 * * *$ \\
\hline & $(0.013)$ & $(0.015)$ & $(0.014)$ \\
\hline $\begin{array}{l}\text { Numbers in parent } \\
* * p<0.05, * p<0 . \\
\text { and quarterly fixec } \\
\text { but are available }\end{array}$ & $\begin{array}{l}\text { esis are stand } \\
\text { Results for sl } \\
\text { effect variable } \\
\text { on request fro }\end{array}$ & $\begin{array}{l}\text { lard errors. ** } \\
\text { ubdivision, bl } \\
\text { es are not repc } \\
\text { om the author }\end{array}$ & $\begin{array}{l}* * p<0.01, \\
\text { lock group, } \\
\text { orted here, } \\
\text { rs }\end{array}$ \\
\hline Total $\mathbf{n}$ & 28,313 & 19,265 & 28,313 \\
\hline Adjusted $\mathbf{R}^{2}$ & 0.93 & 0.94 & 0.94 \\
\hline n (pv homes) & 394 & 159 & 394 \\
\hline Mean non-pv asp2 & $\$ \quad 488,127$ & $\$ \quad 450,223$ & \$ 488,127 \\
\hline Mean size (kW) & 4.0 & 4.3 & 4.0 \\
\hline Estimated \$/Watt & 6.2 & 6.3 & 6.0 \\
\hline
\end{tabular}

\subsection{Age of PV System for Existing Home Hedonic Model Results}

To this point, the marginal impacts to selling prices of each additional $\mathrm{kW}$ of PV added to existing homes have been estimated using the full dataset of existing homes, which has produced an average effect, regardless of the age of the PV system. As discussed previously, it is 
conceivable that older PV systems would garner lower premiums than newer, similarly sized systems. To test this directly, a base model is constructed - see equation (4) - that estimates the marginal impacts for three age groups of PV systems: no more than one year old at the time of sale; between two and four years old; and five or more years old. Results from this model as well as two robustness tests, using the coarsened exact matching procedure and the combined subdivision-block group delineations, are shown in Table 11 as Models 6, 6Ra, and 6Rb, respectively.

Each model finds statistically significant differences between PV and non-PV homes for each age group, and more importantly, premium estimates for newer PV systems are - as expected larger than those for older PV systems and are monotonically ordered between groups, providing some evidence that older systems are being discounted by the buyers and sellers of PV homes. Specifically, the three models estimate an average premium for PV systems that are one year or less in age of \$8.3-9.3/watt, whereas those same models estimate an average premium of \$4.16.1/W for systems that are five or more years old.

\subsection{Returns to Scale Hedonic Model Results}

In the previous modeling, the marginal impacts to selling prices of each additional $\mathrm{kW}$ of PV in the continuous models have been estimated using a linear relationship. To test whether a nonlinear relationship may be a better fit, a SIZE squared term is added to the model as shown in equation (5). Similarly, decreasing or increasing returns to scale might be related to other house characteristics, such as the size of the home (i.e., square feet). This hypothesis is explored using equation (6). Both model results are shown in Table 11 as Model 7 and 8, respectively.

Both models find small and non-statistically significant relationships between their interacted variables, indicating a lack of compelling evidence of a non-linear relationship between PV system size and selling price in the dataset, and a lack of compelling evidence that the linear

relationship is affected by the size of the home. As such, the impact of PV systems on residential selling prices appears to be well approximated by a simple linear relationship, while the size of the home is not found to impact the PV sales price premium. In combination, these results seem to suggest that while California’s tiered rate structures may lead to energy bill savings from PV 
investments that vary non-linearly with PV system size and also vary by home size, those same rate structures have not - to this point - led to any clear impact on the PV premium garnered at the time of home sale. Similarly, though larger PV systems may be installed at a discount to smaller ones on a \$/watt basis, and though any marginal green cachet that exists may diminish with system size, those possible influences are not apparent in the results presented here. 
Table 11: Age of PV System and Return to Scale Hedonic Model Results

\begin{tabular}{|c|c|c|c|c|c|}
\hline & \multicolumn{3}{|c|}{ Age of PV Systems for Existing Homes } & \multicolumn{2}{|c|}{ Returns to Scale } \\
\hline & Base & Robustness & Robustness & Size & Square Feet \\
\hline & & Matched & Subdivision & & \\
\hline & Model 6 & Model 6Ra & Model 6Rb & Model 7 & Model 8 \\
\hline \multirow[t]{2}{*}{ size* $^{*}$ year old } & $0.016 * * *$ & $0.016^{* * *}$ & $0.013^{* * *}$ & & \\
\hline & $(-0.004)$ & $(-0.005)$ & $(-0.004)$ & & \\
\hline \multirow[t]{2}{*}{ size $^{*} 2-4$ years old } & $0.015 * * *$ & $0.010 * * *$ & $0.013^{* * *}$ & & \\
\hline & $(-0.002)$ & $(-0.003)$ & $(-0.002)$ & & \\
\hline \multirow[t]{2}{*}{ size $* 5+$ years old } & $0.012 * * *$ & $0.008 * *$ & $0.008 * *$ & & \\
\hline & $(-0.003)$ & $(-0.004)$ & $(-0.003)$ & & \\
\hline \multirow[t]{2}{*}{ size } & & & & $0.008 * *$ & $0.021 * * *$ \\
\hline & & & & $(0.003)$ & $(0.006)$ \\
\hline \multirow[t]{2}{*}{ sizes qr } & & & & 0.001 & \\
\hline & & & & $(0.001)$ & \\
\hline \multirow[t]{2}{*}{ size* $^{*}$ sqft_1000 } & & & & & -0.003 \\
\hline & & & & & $(0.002)$ \\
\hline \multirow[t]{2}{*}{ sqft_1000 } & $0.256 * * *$ & $0.238 * * *$ & $0.251^{* * *}$ & $0.253 * * *$ & $0.253 * * *$ \\
\hline & $(0.002)$ & $(0.015)$ & $(0.002)$ & $(0.001)$ & $(0.001)$ \\
\hline \multirow[t]{2}{*}{ lt1acre } & $0.373^{* * *}$ & $0.426 * * *$ & $0.376^{* * *}$ & $0.416^{* * *}$ & $0.416^{* * *}$ \\
\hline & $(0.010)$ & $(0.046)$ & $(0.012)$ & $(0.009)$ & $(0.009)$ \\
\hline \multirow[t]{2}{*}{ acre } & $0.019 * * *$ & $0.010 * * *$ & $0.017 * * *$ & $0.016 * * *$ & $0.016 * * *$ \\
\hline & $(0.002)$ & $(0.011)$ & $(0.003)$ & $(0.002)$ & $(0.002)$ \\
\hline \multirow[t]{2}{*}{ ages 2} & $-0.005 * * *$ & $-0.006 * * *$ & $-0.005 * * *$ & $-0.004 * * *$ & $-0.004 * * *$ \\
\hline & $(0.000)$ & $(0.002)$ & $(0.000)$ & $(0.000)$ & $(0.000)$ \\
\hline \multirow[t]{2}{*}{ ages 2 sqr } & $0.000 * * *$ & $0.000 * * *$ & $0.000 * * *$ & $0.000 * * *$ & $0.000 * * *$ \\
\hline & $(0.000)$ & $(0.000)$ & $(0.000)$ & $(0.000)$ & $(0.000)$ \\
\hline \multirow[t]{2}{*}{ bgre_100 } & $0.002 * * *$ & $-0.002 * * *$ & $0.002 * * *$ & $0.003 * * *$ & $0.003 * * *$ \\
\hline & $(0.001)$ & $(0.009)$ & $(0.001)$ & $(0.001)$ & $(0.001)$ \\
\hline \multirow[t]{2}{*}{ intercept } & $12.820 * * *$ & $13.024^{* * *}$ & $12.834^{* * *}$ & $12.702 * * *$ & $12.701^{* * *}$ \\
\hline & $(0.013)$ & $(0.078)$ & $(0.014)$ & $(0.010)$ & $(0.011)$ \\
\hline
\end{tabular}

Numbers in parenthesis are standard errors. ${ }^{* * *} p<0.01,{ }^{* *} p<0.05,{ }^{*} p<0.1$

Results for subdivision, block group, and quarterly fixed effect variables are not reported here, but are available upon request from the authors

\begin{tabular}{|c|c|c|c|c|c|c|}
\hline Total n & 44,384 & 4,887 & 44,384 & 72,319 & & 72,319 \\
\hline Adiusted R ${ }^{2}$ & 0.93 & 0.95 & 0.94 & 0.93 & & 0.93 \\
\hline n (pv homes) & 897 & 618 & 897 & 1,894 & & 1,894 \\
\hline Mean non-pv asp2 & 532,645 & 590,428 & 532,645 & 480,862 & $\$$ & 480,862 \\
\hline Mean size (kW) & 3.8 & 3.7 & 3.8 & 3.1 & & 3.1 \\
\hline Estimated \$/Watt & $\$ 8.3-\$ 6.1$ & $\$ 9.3-\$ 4.9$ & $\$ 7.0-\$ 4.1$ & 6.3 & $\$$ & 6.4 \\
\hline
\end{tabular}

Note: $\$$ /watt estimates for Returns to Scale models include the non-statistically significant interaction coefficients and therefore should be interpreted with caution 


\section{Conclusions}

The market for solar PV is expanding rapidly in the U.S. Almost 100,000 PV systems have been installed in California alone, more than 90\% of which are residential. Some of those "PV homes" have sold, yet little research exists estimating if those homes sold for significantly more than similar non-PV homes. Therefore, one of the claimed incentives for solar homes - namely that a portion of the initial investment into a PV system will be recouped if the home is sold - has, to this point, been based on limited evidence. Practitioners have sometimes transferred the results from past research focused on energy efficiency and energy bills more generally and, while recent research has turned to PV that research has so far focused largely on smaller sets of PV homes concentrated in certain geographic areas. Moreover, the home sales price effect of PV on a new versus an existing home has not previously been the subject of research. Similarly unexplored has been whether the relationship of PV system size to home sales prices is linear, and/or is affected by either the size of the home or the age of the PV system.

This research has used a dataset of approximately 72,000 California homes, approximately 2,000 of which had PV systems installed at the time of sale, and has estimated a variety of different hedonic and repeat sales models to directly address the questions outlined above. Moreover, an extensive set of robustness tests were incorporated into the analysis to test and bound the possible effects and increase the confidence of the findings by mitigating potential biases. The research was not intended to disentangle the various individual underlying influences that might dictate the level of the home sales price premium caused by PV, such as, energy costs savings, the net (i.e., after applicable state and federal incentives) installed cost of the PV system, the possible presence of a green cachet, or seller attributes. Instead, the goal was to establish credible estimates for the aggregate PV residential sale price effect across a range of different circumstances (e.g., new vs. existing homes, PV system age).

The research finds strong evidence that homes with PV systems in California have sold for a premium over comparable homes without PV systems. More specifically, estimates for average PV premiums range from approximately $\$ 3.9$ to $\$ 6.4$ per installed watt (DC) among a large number of different model specifications, with most models coalescing near $\$ 5.5 /$ watt. That 
value corresponds to a premium of approximately $\$ 17,000$ for a relatively new 3,100 watt PV system (the average size of PV systems in the study). These results are similar to the average increase for PV homes found by Dastrop et al. (2010), which used similar methods but a different dataset, one that focused on homes in the San Diego metropolitan area. Moreover, these average sales price premiums appear to be comparable to the average net (i.e., after applicable state and federal incentives) installed cost of California residential PV systems from 2001-2009 (Barbose et al., 2010) of approximately \$5/watt, and homeowners with PV also benefit from electricity cost savings after PV system installation and prior to home sale.

Although the results for the full dataset from the variety of models are quite similar, when the dataset is split among new and existing homes, PV system premiums are found to be markedly affected, with new homes demonstrating average premiums of \$2.3-2.6/watt, while existing homes are found to have average premiums of $\$ 6-7.7 /$ watt. Possible reasons for this disparity between new and existing PV homes include: differences in underlying net installation costs for PV systems; a willingness among builders of new homes to accept a lower PV premium because PV systems provide other benefits to the builders in the form of product differentiation, leading to increased sales velocity and decreased carrying costs; and, lower familiarity and/or interest in marketing PV systems separately from the other features of new homes contrasted with a likely strong familiarity with the PV systems among existing home sellers.

The research also investigated the impact of PV system age on the sales price premium for existing homes, finding - as would be expected - evidence that older PV systems are discounted in the marketplace as compared to newer PV systems. Finally, evidence of returns to scale for either larger PV systems or larger homes was investigated but not found.

In addition to benchmarking the results of this research to the limited previous literature investigating the sales price premiums associated with $\mathrm{PV}$, our results can also be compared to previous literature investigating premiums associated with energy efficiency (EE) or, more generally, energy cost savings. A number of those studies have converted this relationship into a ratio representing the relative size of the home sales price premium to the annual savings expected due to energy bill reductions. These ratios have ranged from approximately 7:1 
(Longstreth et al., 1984; Horowitz and Haeri, 1990), to 12:1 (Dinan and Miranowski, 1989), to approximately 20:1 (Johnson and Kaserman, 1983; Nevin et al., 1999; Eichholtz et al., 2009), and even as high as 31:1 (Nevin and Watson, 1998).

Although actual energy bill savings from PV for the sample of homes used for this research were not available, a rough estimate is possible, allowing for a comparison to the previous results for energy-related homes improvements and energy efficiency. Specifically, assuming that 1,425 kWh (AC) are produced per year per kW (DC) of installed PV on a home (Barbose et al., 2010; CPUC, 2010) ${ }^{43}$ and that this production offsets marginal retail electricity rates that average \$0.20/kWh (AC) (Darghouth et al., 2010), each watt (DC) of installed PV can be estimated to save \$0.29 in annual energy costs. Using these assumptions, the \$/watt PV premium estimates reported earlier can be converted to sale price to annual energy savings ratios (see Figure 5).

A \$3.9 to \$6.4/watt premium in selling price for an average California home with PV installed equates to a 14:1 to 22:1 sale price to energy savings ratio, respectively. For new homes, with a $\$ 2.3-2.6 /$ watt sale price premium, this ratio is estimated to be 8:1 or 9:1, and for existing homes, with an overall sale price premium range of \$6-7.6/watt, the ratio is estimated to range from 21:1 to 26:1. Without actual energy bill savings, these estimates are somewhat speculative, but nonetheless are broadly consistent with the previous research that has focused on EE-based home energy improvements.

\footnotetext{
${ }^{43}$ The 1,425 kWh (AC) estimate is based on a combination of a 19\% capacity factor (based on AC kWh and CECAC kW) from CPUC (2010), and an 0.86 conversion factor between CEC-AC kW and DC kW (Barbose et al., 2010).
} 


\section{Figure 5: Estimated Ratios of Sale Price Premium to Annual Energy Cost Savings}

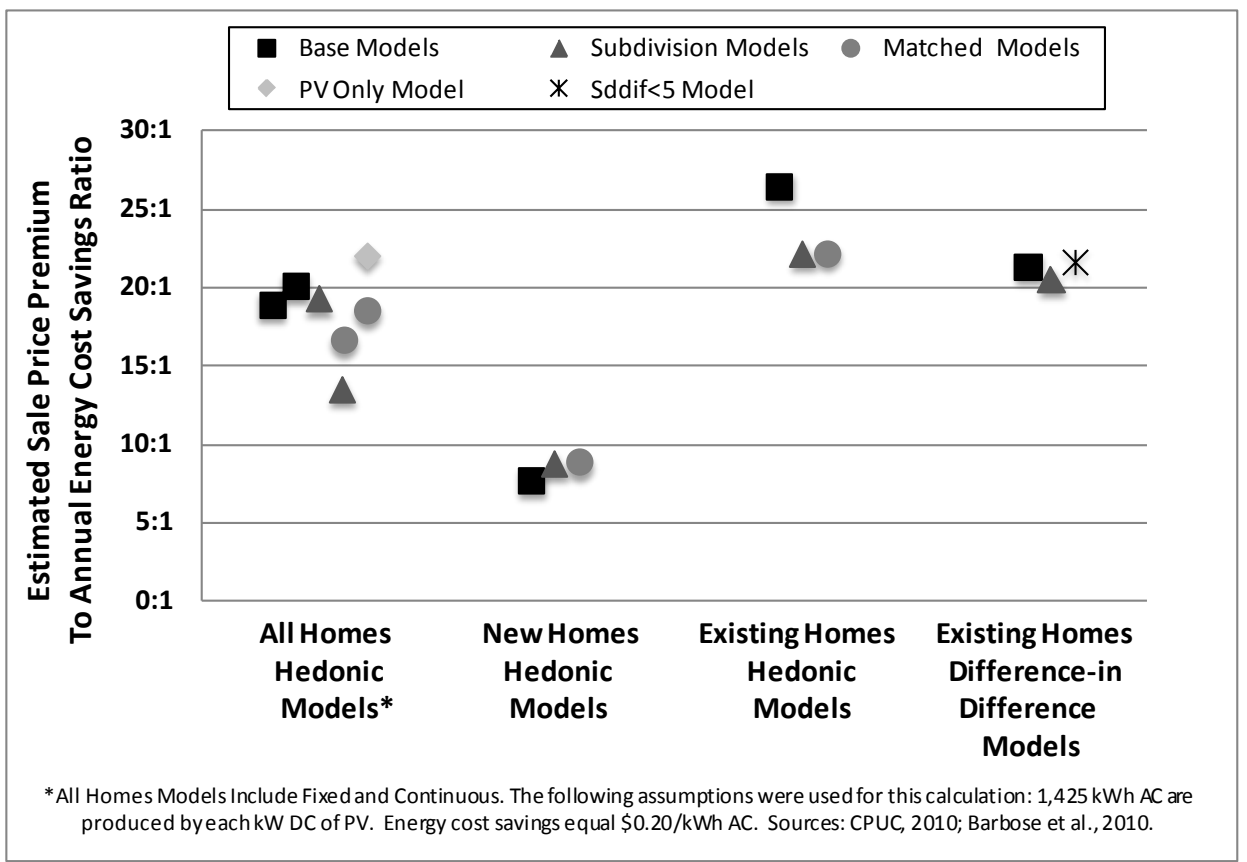

Although this research finds strong evidence that homes with PV systems in California have sold for a premium over comparable homes without PV systems, the extrapolation of these results to different locations or market conditions (e.g., different retail rates or net installed costs) should be done with care.

Finally, additional questions remain that warrant further study. Perhaps most importantly, although the dataset used for this analysis consists of almost 2,000 PV homes, the study period was limited to sales occurring prior to mid-2009 and the dataset was limited to California. Future research would therefore ideally include more-recent sales from a broader geographic area to better understand any regional/national differences that may exist as well as any changes to PV premiums that occur over time as the market for PV homes and/or the net installed cost of PV changes. More research is also warranted on new versus existing homes to better understand the nature and underlying drivers for the differential premium discovered in this research; in addition to further hedonic analysis, that research could include interviewing/surveying home builders and buyers and exploring the impact of demographic, socio-economic, and others factors on the PV premium. 
Additionally, future research might compare sales price premiums to actual annual home energy cost savings, to not only to explore the sale price to annual energy cost savings ratio directly, but also to explore if a green cachet exists over and above any sale price premiums that would be expected from energy cost savings alone. Further, house-by-house PV system and other information not included in the present study might be included in future studies, such as the actual net installed costs of PV for individual households, rack-mounted or roof-integrated distinctions as well as other elements of PV system design, the level of energy efficiency of the home, whether the home has a solar hot water heater, whether the PV system is customer or $3^{\text {rd }}$ party owned at the time of sale, and if the homeowner can sell the green attributes the system generates. ${ }^{44}$ Such research could elucidate important differences in PV premiums among households, PV system designs and state and federal programmatic designs, as well as bolster confidence in the magnitude of the PV premium estimated here. Finally, and more generally, additional research could investigate the impact of PV systems on the time homes remain on the market before sale, a factor that may be especially important for large developers and sellers of new homes.

${ }^{44} 3^{\text {rd }}$ party owned PV systems would not be expected to command the same sort of premium as was discovered here. Although the level of penetration of $3^{\text {rd }}$ party owners in our data was not significant (below $10 \%$ ), and therefore would likely have not influenced our results in a substantive way, any future research, using more recent data, must account for their inclusion specifically. 


\section{References}

Barbose, G., Darghouth, N. and Wiser, R. (2010) Tracking the Sun III: The Installed Cost of Photovoltaics in the U.S. From 1998-2009. Lawrence Berkeley National Laboratory, Berkeley, CA. December 2010. 54 pages. LBNL-4121E.

Black, A. (2010) Does It Pay? Figuring the Financial Value of a Solar or Wind Energy System. Solar Today. Fall/Winter 2010. pp. 26-27.

Brounen, D. and Kok, N. (2010) On the Economics of Energy Labels in the Housing Market. Program on Housing and Urban Policy: Working Papers Series. Prepared for Institute of Business and Economic Research and Fisher Center for Real Estate and Urban Economics, University of California, Berkeley, CA. August 2010. 34 pages. W10002.

California Energy Commission (CEC) (2002) Consultant Report: Renewable Energy Study. The Phelps Group and ICF Consulting. Prepared for California Energy Commission (CEC). November 2001. 77 pages.

California Public Utilities Commission (CPUC) (2010) CPUC California Solar Initiative: 2009 Impact Evaluation. Final Report. Prepared by: Itron and KEMA. Prepared for California Public Utilities Commission, Energy Division. June 2010. 632 pages.

Cook, R. D. (1977) Detection of Influential Observations in Linear Regression. Technometrics. 19(1): 15-18.

Dakin, W., Springer, D. and Kelly, B. (2008). Case Study: The Effectiveness of Zero Energy Home Strategies in the Marketplace. Presented at ACEEE Summer Study on Energy Efficiency in Buildings, Pacific Grove, California. August 17-22, 2008.

Darghouth, N., Barbose, G. and Wiser, R. (2010) The Impact of Rate Design and Net Metering on the Bill Savings from Distributed PV for Residential Customers in California. Lawrence Berkeley National Laboratory, Berkeley, CA. December 2010. 62 pages. LBNL-3276E.

Dastrop, S., Zivin, J. G., Costa, D. L. and Kahn, M. E. (2010) Understanding the Solar Home Price Premium: Electricity Generation and “Green” Social Status. Working Paper Series. Prepared for UC Center for Energy and Environmental Economics, Berkeley, CA. December 9, 2010. 29 pages. E3 WP-001.

Dinan, T. M. and Miranowski, J. A. (1989) Estimating the Implicit Price of Energy Efficiency Improvements in the Residential Housing Market: A Hedonic Approach. Journal of Urban Economics. 25(1): 52-67.

Durbin, J. and Watson, G. S. (1951) Testing for Serial Correlation in Least-Squares Regression. Biometrika. 38(1-2): 159-178. 
Eichholtz, P., Kok, N. and Quigley, J. M. (2009) Doing Well by Doing Good? An Analysis of the Financial Performance of Green Office Buildings in the USA. University of California. Institute of Business and Economic Research. Berkeley Program on Housing and Urban Policy, Berkeley, CA. April 1, 2008. 49 pages. W08-001S.

Eichholtz, P., Kok, N. and Quigley, J. M. (2011) The Economics of Green Building. Working Paper Series Prepared for UC Center for Energy and Environmental Economics $\left(\mathrm{UCE}^{3}\right)$, Berkeley, CA. January 2011. 35 pages. WP-002.

Farhar, B. and Coburn, T. (2008) A New Market Paradigm for Zero-Energy Homes: A Comparative Case Study. Environment: Science and Policy for Sustainable Development 50(1): 18-32.

Farhar, B. and Coburn, T. C. (2006) A New Market Paradigm for Zero-Energy Homes: The Comparative San Diego Case Study. Volume 1 of 2. Prepared for National Renewable Energy Laboratory, Bolder, CO. December 2006. 413 pages. NREL/TP-550-38304-01.

Farhar, B. C., Coburn, T. C. and Murphy, M. (2004a) Comparative Analysis of Home Buyer Response to New Zero-Energy Homes. Summer Study on Energy Efficiency in Buildings, August 22-27, 2004. Prepared for American Council for an Energy-Efficient Economy, Pacific Grove, California. Preprinted in July, 2004. NREL/CP-550-35912.

Farhar, B. C., Coburn, T. C. and Murphy, M. (2004b) Large-Production Home Builder Experience with Zero Energy Homes. Summer Study on Energy Efficiency in Buildings, August 22-27, 2004. Prepared for American Council for an Energy-Efficient Economy, Pacific Grove, California. Preprinted in July, 2004. 15 pages. NREL/CP-550-35913.

Freeman, A. M. (1979) Hedonic Prices, Property Values and Measuring Environmental Benefits: A Survey of the Issues. Scandinavian Journal of Economics. 81(2): 154-173.

Griffin, A., Kaufman, B. and Hamilton, S. (2009) Certified Home Performance: Assessing the Market Impacts of Third Party Certification on Residential Properties. Earth Advantage Institute. Prepared for Green Building Value Initiative Steering Committee, Portland, OR. May 29, 2009. 36 pages.

Gujarati, D. N. (2003) Basic Econometrics. McGraw-Hill/Irwin. Fourth Edition, New York. 1002 pages. ISBN 0-07-233542-4.

Hoen, B., Wiser, R., Cappers, P., Thayer, M. and Sethi, G. (2009) The Impact of Wind Power Projects on Residential Property Values in the United States: A Multi-Site Hedonic Analysis. Lawrence Berkeley National Laboratory, Berkeley, CA. December, 2009. 146 pages. LBNL-2829E.

Horowitz, M. J. and Haeri, H. (1990) Economic Efficiency vs. Energy Efficiency: Do Model Conservation Standards Make Good Sense? Energy Economics. 12(2): 122-131.

Johnson, R. C. and Kaserman, D. L. (1983) Housing Market Capitalization of Energy-Saving Durable Good Investments. Economic Inquiry. 21: 374 - 386. 
King, G., Blackwell, M., Iacus, S. and Porro, G. (2010) Cem: Coarsened Exact Matching in Stata. Stata Journal. 9(4): 524-546.

Laquatra, J. (1986) Housing Market Capitalization of Thermal Integrity. Energy Economics. 8(3): 134-138.

Longstreth, M., Coveney, A. R. and Bowers, J. S. (1984) Conservation Characteristics among Determinants of Residential Property Value. Journal of Consumer Research. 11(1): 564571.

Malpezzi, S. (2003) Hedonic Pricing Models: A Selective and Applied Review. Section in Housing Economics and Public Policy: Essays in Honor of Duncan Maclennan. WileyBlackwell. Hoboken, NJ. pp. 67-85 of 328 pages. ISBN 978-0-632-06461-8.

McCabe, M. and Merry, L. (2010) Resale Market Value of Residential Solar PV. Journal of Sustainable Real Estate. Volume 2. Industry Perspectives. Retrieved March 28, 2011 from http://www.costar.com/josre/industryPerspectives.htm

Nevin, R., Bender, C. and Gazan, H. (1999) More Evidence of Rational Market Values for Energy Efficiency. The Appraisal Journal. 67(4): 454-460.

Nevin, R. and Watson, G. (1998) Evidence of Rational Market Values for Home Energy Efficiency. The Appraisal Journal. 68: 401-409.

Rosen, S. (1974) Hedonic Prices and Implicit Markets: Product Differentiation in Pure Competition. Journal of Political Economy. 82(1): 34-55.

Simons, R. A. and Saginor, J. D. (2006) A Meta-Analysis of the Effect of Environmental Contamination and Positive Amenities on Residential Real Estate Values. Journal of Real Estate Research. 28(1): 71-104.

Sirmans, G. S., Lynn, M., Macpherson, D. A. and Zietz, E. N. (2005a). The Value of Housing Characteristics: A Meta Analysis. Presented at Mid Year Meeting of the American Real Estate and Urban Economics Association. May 2005.

Sirmans, G. S., Macpherson, D. A. and Zietz, E. N. (2005b) The Composition of Hedonic Pricing Models. Journal of Real Estate Literature. 13(1): 3-42.

Solar Energy Industries Association (SEIA) and GTM Research (GTM) (2011) U.S. Solar Market Insight - 2010 Year in Review. GTM Research (GTM) in Boston MA. Prepared for Solar Energy Industries Association (SEIA), Washington, DC.

SunPower (2008) New Homes With SunPower Solar Systems are Bright Spot in Market. Press Release Regarding Ryness Corporation Report. June 24, 2008

White, H. (1980) A Heteroskedasticity-Consistent Covariance Matrix Estimator and a Direct Test for Heteroskedasticity. Econometrica. 48(4): 817-838. 
Wooldridge, J. (2009) Introductory Econometrics: A Modern Approach. South Western Cengage Learning. Mason, OH. ISBN\# 0324660545. 